This is the author's final, peer-reviewed manuscript as accepted for publication. The publisher-formatted version may be available through the publisher's web site or your institution's library.

\title{
Fusarium head blight resistance in U.S. winter wheat cultivars and elite breeding lines
}

Feng Jin, Dadong Zhang, William Bockus, P. Stephen Baenziger, Brett Carver and Guihua Bai

\section{How to cite this manuscript}

If you make reference to this version of the manuscript, use the following information:

Jin, F., Zhang, D., Bockus, W., Baenziger, P. S., Carver, B., \& Bai, G. (2013). Fusarium head blight resistance in U.S. winter wheat cultivars and elite breeding lines. Retrieved from http://krex.ksu.edu

\section{Published Version Information}

Citation: Jin, F., Zhang, D., Bockus, W., Baenziger, P. S., Carver, B., \& Bai, G. (2013). Fusarium head blight resistance in U.S. winter wheat cultivars and elite breeding lines. Crop Science, 53(5), 2006-2013.

Copyright: (C) Crop Science Society of America

Digital Object Identifier (DOI): doi:10.2135/cropsci2012.09.0531

Publisher's Link: https://www.crops.org/publications/cs/articles/53/5/2006

This item was retrieved from the K-State Research Exchange (K-REx), the institutional repository of Kansas State University. K-REx is available at http://krex.ksu.edu 


\title{
Fusarium head blight resistance in U.S. winter wheat cultivars and elite breeding lines
}

\author{
Feng Jin, Dadong Zhang, William Bockus, P. Stephen Baenziger, Brett Carver and Guihua Bai ${ }^{*}$
}

\section{Abstract}

Fusarium (Fusarium graminearum) head blight (FHB) is a destructive disease of wheat (Triticum aestivum L.) worldwide. To characterize FHB resistance in U.S. wheat germplasm, 363 U.S. winter wheat accessions were repeatedly evaluated for FHB resistance. A high correlation $(r=$ $0.73, P<0.001)$ for mean percentages of symptomatic spikelets (PSS) was observed between greenhouse and field experiments. The majority of tested accessions were either moderately or highly susceptible; only $7 \%$ of the accessions in the greenhouse and $6 \%$ of the accessions in the field showed a high level of resistance. Mean PSS for 19 accessions that carry markers for Fhb1, a major quantitative trait locus (QTL) from 'Sumai3', are 29.8\% in the greenhouse and 25.1\% in the field experiments. Fifty-four wheat accessions lacking Fhb1 showed at least a moderately high level of FHB resistance in the greenhouse and/or field. These included three resistant accessions, 35 moderately resistant accessions, and 16 accessions that showed different levels of resistance in greenhouse and field experiments. Accessions without Fhb1 that showed consistent resistance in both field and greenhouse experiments may be good sources for pyramiding native resistance QTLs from U.S. wheat with Fhb1.

\footnotetext{
Abbreviations: FHB, Fusarium head blight; HWW, hard winter wheat; SWW, soft winter wheat; NIL, near-isogenic lines; PSS, percentage of symptomatic spikelets in a spike; QTL, quantitative trait locus; R, resistant; MR, moderately resistant; MS, moderately susceptible; S, susceptible

F. Jin, College of Agronomy, Northwest A\&F University, Yangling, Shaanxi, China, 712100; F. Jin, D. Zhang, and G. Bai, Department of Agronomy, Kansas State University, Manhattan, KS 66506; W. Bockus, Department of Plant
} 
1 Pathology, Kansas State University, Manhattan, KS 66506; P. S. Baenziger, University of Nebraska, Lincoln, NE

2 68583; B. F. Carver, Oklahoma State University, Stillwater, OK 74078; G-H. Bai, USDA-ARS Hard Winter Wheat

3 Genetics Research Unit, Manhattan, KS 66506. *Corresponding author (guihua.bai@ars.usda.gov, gbai@ksu.edu). 4

5 Contribution number 13-024-J from the Kansas Agricultural Experiment Station. This project is partly funded by the 6 U.S. Wheat and Barley Scab Initiative and the National Research Initiative Competitive Grants CAP project 7 2011-68002-30029 from the USDA National Institute of Food and Agriculture. USDA is an equal opportunity 8 provider and employer. Mention of trade names or commercial products in this article is solely for the purpose of 9 providing specific information and does not imply recommendation or endorsement by the U.S. Department of 10 Agriculture. 
1 Fusarium head blight (FHB, incited by Fusarium spp.) of wheat (Triticum aestivum), also known

2 as wheat scab, is one of the most destructive diseases in the humid and semi-humid wheat-growing areas worldwide (Parry et al., 1995; Osborne and Stein, 2007). F. graminearum

4 Schwabe [teleomorph $=$ Gibberella zeae $(\mathrm{Schw}$.$) Petch] is the prevailing wheat pathogen in the$ 5 United States and many other countries (Bai and Shaner, 2004). Severe FHB epidemics occur when a susceptible host encounters abundant pathogen inocula in the presence of humid and warm weather during wheat anthesis (Osborne and Stein, 2007). FHB epidemics can cause significant losses in both grain yield and quality. Harvested grain contaminated with mycotoxins, especially deoxynivalenol (DON), produced by the pathogen is a serious safety concern to human and animal health (Bai and Shaner, 1994; Parry et al., 1995).

Use of resistant cultivars coupled with fungicide application is the most effective strategy to minimize disease losses. In China, a nationwide screening of germplasm and breeding lines identified 'Sumai 3' and its derivatives to have the best resistance (Reviewed by Bai and Shaner, 1994, 2004), which have become the major sources of FHB resistance in breeding programs worldwide. Quantitative trait loci (QTLs) for FHB resistance have been reported on all 21 chromosomes (Bai and Shaner 2004, Yu et al, 2008, 1963 Liu et al, 2009, Buerstmayr et al., 2009). However, only the Fhb1 QTL on chromosome 3BS has a large effect mainly on type II resistance, resistance to fungal spread within a spike (Schroeder, and Christensen, 1963), that has been stable across various genetic backgrounds (Bai and Shaner, 2004). In the United States, FHB epidemics originally occurred mainly in hard spring wheat in the northern Great Plains and in soft winter wheat (SWW) regions, so extensive screening of breeding materials from those 
regions has identified several U.S. cultivars with FHB resistance, such as 'Roane', 'Ernie', and 'Freedom' (Rudd et al., 2001, Griffey et al., 2001). QTL haplotype analysis indicates that these cultivars do not carry Fhb1, which means they may carry resistance QTLs that are different from those in Chinese sources (Liu et et al., 2005). In the hard winter wheat (HWW) growing region of the Great Plains, FHB has not been a major issue until recent years; thus, systematic screening of HWW germplasm and breeding materials for FHB resistance has not been reported. Initial evaluation of some HWW identified several cultivars, including 'Heyne' and 'Hondo', with FHB resistance. QTLs in these cultivars may be different from those in Asian sources (Zhang et al. 2012). Combining U.S. native resistance genes with the resistance alleles at major QTLs from Asian sources may diversify the FHB resistance gene pool and significantly enhance FHB resistance levels in U.S. wheat. Therefore, characterizing U.S. winter wheat, especially HWW elite breeding lines, may provide important information to breeders for selecting good parents for breeding crosses. This study was designed to evaluate the effects of Fhb1 on FHB resistance in U.S. winter wheat backgrounds, to identify native sources of FHB resistance, and to investigate wheat accessions with resistance type I (to initial infection) and type II by comparing reactions to FHB in greenhouse and field experiments.

MATERIALS AND METHODS

\section{Plant materials}

A total of 363 winter wheat accessions, including 289 HWW and 74 SWW accessions, were evaluated for FHB resistance in both greenhouse and field experiments. HWW accessions were 
selected from five hard winter wheat nurseries: the 2008 and 2010 Southern and Northern HWW

Regional Performance Nurseries, the 2010 HWW Regional Germplasm Observation Nursery, the 2010 Tri-state FHB Nursery, and the 2008 Yield Trial Nursery from the wheat breeding program at Oklahoma State University. SWW accessions were selected from Uniform Eastern Soft Red Winter Wheat Nurseries and Uniform Southern Soft Red Winter Wheat Nurseries. The project consisted of two sets of materials tested in different experiments: set I had 207 accessions, including all of the HWW and SWW entries from the 2008 nurseries and breeding lines from Oklahoma; and set II had 191 accessions, including 156 new accessions from the 2010 HWW nurseries, and 35 selected accessions from experiment I. In both sets, Sumai3 (resistant), 'Wesley'

10 (moderately susceptible), and 'Duster' (susceptible) were used as controls.

Evaluation of FHB resistance

In the greenhouse experiments, six plants per line were transferred into a $13 \mathrm{x} 13 \mathrm{~cm}$ Dura-pot (Hummert Int., Earth City, MO) with a 12 h photoperiod after vernalization for 6 wk at $4{ }^{\circ} \mathrm{C}$ in a cold chamber. Set I was tested in 2009 (spring and fall) and 2010 (spring) greenhouse experiments, and set II was tested in 2011 (spring and fall) and 2012 (spring) greenhouse replications (pots) of six plants in each experiment.

Conidial inocula of F. graminearum were prepared using field isolate GZ 3639 from Kansas. This isolate has showed consistent pathogenicity on a set of wheat cultivars for over a decade (G. Bai, unpublished data). Conidial suspension was adjusted to 100 spores per $\mu \mathrm{L}$ for inoculation. 
1 About six spikes with similar flowering time in each pot were inoculated by injecting $10 \mu \mathrm{L}$ of

2 the conidial suspension into a central spikelet of a spike at anthesis using a syringe. After

3 inoculation, plants were moved into a moist chamber with $100 \%$ relative humidity for $48 \mathrm{~h}$ at 21

$4 \pm 5{ }^{\circ} \mathrm{C}$ to initiate infection. Infected plants were then moved to a greenhouse bench for disease

5 development at $21 \pm 5{ }^{\circ} \mathrm{C}$ during the day and $17 \pm 2{ }^{\circ} \mathrm{C}$ during the night. About $15 \mathrm{~d}$

6 post-inoculation, when the susceptible control was completely blighted, the numbers of infected

7 and total spikelets in each inoculated spike were counted to calculate the percentage of

8 symptomatic spikelets (PSS) in a spike.

9 Field experiments were conducted in the Rocky Ford FHB Nursery of the Department of

10 Plant Pathology, Kansas State University (Manhattan, KS). Set I was evaluated for FHB in the

11 springs of 2009, 2010, and 2011, and set II was evaluated in the springs of 2011 and 2012. About

1240 seeds per accession were planted in a 1-m-long single-row plot, and each experiment had two

13 replications. The FHB nursery was inoculated using spawn inoculation, in which $F$.

14 graminearum-infected corn (Zea mays L.) kernels were scattered on the soil surface at the

15 booting stage and $2 \mathrm{wk}$ afterwards to facilitate initial infection. To ensure FHB infection in early

16 flowering plants, needle inoculation was also conducted as described for greenhouse inoculation

17 with six spikes per plot to assess type II resistance. From flowering through early dough stages,

18 the nursery was misted by sprinklers $10 \mathrm{~min}$ per $\mathrm{h}$ from $1700 \mathrm{~h}$ to $0700 \mathrm{~h}$ daily. PSS was

19 estimated for all plots on the basis of overall performance of a plot at $21 \mathrm{~d}$ after needle

20 inoculation. PSS data were rechecked after $3 \mathrm{~d}$.

21 All accessions were classified into one of four categories based on their PSS: resistant (R), 
moderately resistant (MR), moderately susceptible (MS), and susceptible (S). Classification decisions were made by comparing mean FHB rating of each accession with the $95 \%$ confidence intervals of R, MS, and S controls. Accessions falling between R and MS were classified as MR.

\section{DNA extraction and marker analysis}

Leaf tissue was collected at the two-leaf stage, and genomic DNA was isolated using a cetyltrimethyl ammonium bromide (CTAB) method (Zhang et al. 2012). A sequence tagged site marker, Xumn10, was used to identify whether the Fhb1 resistance allele was present (Liu et al., 2008), and a single nucleotide polymorphism marker, Xsnp3BS-8, for Fhb1 was analyzed to verify Fhb1 resistance allele (Bernardo et al., 2012). DNA sequencing for Xsnp3BS-8 was done for these accessions that did not provide useful single nucleotide polymorphism results. Polymerase chain reaction was performed following Sun et al. (2010), and DNA sequencing was done using a BigDye ${ }^{\circledR}$ Terminator V1.1 sequencing kit (Applied Biosystems, Foster City, CA).

\section{Data Analysis}

Analysis of variance (ANOVA) and regression analysis were conducted using SAS ver. 9.2 (SAS Institute, Inc., Cary, NC). Because two sets of materials were selected from Regional Performance Nurseries in two different years (2008 and 2010), they were evaluated for FHB in different sets of greenhouse and field experiments. To investigate if any significant PSS differences existed between the two sets of experiments, ANOVA was conducted for both greenhouse and field PSS data for 35 common accessions that were tested in both sets of experiments. 


\section{Results}

Wheat reactions to Fusarium head blight in greenhouses

4 The difference in PSS for the 35 accessions that were common to both sets of materials was not

5 significant between the two sets of greenhouse experiments, nor among three tests of each set, nor between replications in each test (data not shown); thus, the two sets of materials were combined for further data analysis. Correlation coefficients of PSS for 363 accessions were highly significant among the three greenhouse experiments $(r=0.53-0.67, P<0.001)$. Wheat accessions showed significant variation in PSS after single floret inoculation (Fig. 1). Control cultivars Sumai3 (R), Wesley (MS), and Duster (S) had an average PSS of 8.6\%, 51.5\%, and $81.3 \%$, respectively. Frequency distribution of PSS showed that most accessions (75.0\%) were either as susceptible as Duster $(43.0 \%$ with PSS $\geqslant 70.1 \%)$ or as moderately susceptible (32.0\% with PSS between $45.1 \%$ and $70.0 \%$ ) as Wesley (Fig. 1 and Table 1). Among the 363 wheat accessions, only $25(7.0 \%)$ were classified as resistant, with a PSS $\leqslant 23.0 \%$, and 64

15 (18.0\%) were moderately resistant, with a PSS between $23.1 \%$ and $45.0 \%$ (Table 1 ).

To test for the presence of the Fhb1-resistant allele in the resistant wheat accessions, marker Xumn10 was analyzed in all accessions. A total of 23 wheat accessions had the 258-bp marker allele associated with the Fhb1 resistance allele. Among them, 16 were backcross-derived Fhb1 NILs from the USDA marker-assisted backcross project (G. Bai, unpublished data). In these accessions, the Fhb1 resistance allele had been transferred into three U.S. HWW cultivars (Wesley, 'Trego', and 'Harding') and one SWW cultivar ('Clark') (Table 
1 2). They all showed a high level of resistance in greenhouse experiments, except for single Fhb1

2 lines from Trego and Clark, and two from Harding that had slightly higher PSS estimates.

3 Among the seven other lines carrying the Xumn10 allele associated with Fhb1 resistance, four

4 lines (INW0411, P02444A1-23-9, NE08527, and P03112A1-7-14) were resistant or moderately

5 resistant to $\mathrm{FHB}$, and three (BC01007-7, VA05W-258, and NX03Y2489) were moderately

6 susceptible or susceptible. To verify the presence of the Fhb1 resistance allele in these

7 accessions, the polymorphic nucleotide sequence at a recently developed single nucleotide

8 polymorphism marker, Xsnp3BS-8, was assayed. All 16 Fhb1 NILs had the Sumai3 allele G

9 (Table 2). Among the other seven Fhb1 lines with the Xumn10 marker allele associated with resistance, only three (INW0411, P02444A1-23-9, and P03112A1-7-14) carry the Xsnp3BS-8 allele that is associated with resistance. Two (NE08527 and VA05W-258) carry the allele C associated with a susceptible reaction, and two (BC01007-7 and NX03Y2489) did not produce PCR products. Seventeen accessions did not carry the Fhb1 resistance allele, but still showed a high level of type II resistance, with a mean PSS of $17.4 \%$ (Table 2). These materials likely contain resistance QTLs other than Fhb1, and include wheat accessions SD05085-1, T154, SD05210, 'Century', Heyne, 'Lyman', 'Everest', 'Harry', Freedom, and 'Atlas66' (Table 2). The markers Xumn10 or Xsnp3BS-8 (Table 2). Therefore, Fhb1 can significantly improve FHB resistance in many genetic backgrounds. than in HWW (20.0\%) (Table 1). In HWW, the percentage is even lower $(17.0 \%)$ after removal 
of Fhb1 NILs; thus, HWW appears to have a much lower percentage of breeding lines or cultivars with FHB type II resistance than SWW (Table 2, Supplemental Table S1). Wheat reactions to Fusarium head blight in the field In the two sets of field experiments, the difference in PSS for the 35 accessions common to both sets was not significant between the two sets of field experiments (data not shown) and the correlation coefficients of the 35 accessions were significant (Supplemental Table S2). Therefore, they were combined for further statistical analysis. The field mean PSS for the three controls, Sumai3 (R), Wesley (MS) and Duster (S), increased slightly from the greenhouse data, so PSS ranges for the four phenotypic classes were adjusted accordingly for field data, with a PSS of 0 to $25.0 \%$ classified as $\mathrm{R}, 25.1$ to $50.0 \%$ as $\mathrm{MR}, 50.1$ to $75.0 \%$ as $\mathrm{MS}$, and above $75.0 \%$ as $\mathrm{S}$. Among the 363 accessions, only 22 were R (10 HWW and 12 SWW), and 98 were MR. A about $71.0 \%$ were MS or S to FHB in the field conditions (Table 1).

The 19 wheat accessions containing the Fhb1-associated alleles of both markers Xumn10 and Xsnp3BS-8 all had FHB resistance, with a mean PSS of $25.1 \%$ in the field experiments (Table 2). Among them, 16 Fhb1 NILs had consistent resistance similar to that observed in the reducing FHB severity both in greenhouse and field conditions. Among the 22 resistant accessions identified in the field experiments, three HWW and seven SWW accessions did not have the Xumn10 allele associated with Fhb1 resistance (Table 1, Table 2). The HWW entries consisted of both breeding lines and released cultivars from different states, including T154, 
'Hitch', and KS08IFAFS1. Resistant SWW cultivars or breeding lines from several states

2 included IL02-18228, Roane, USG3555, and KY96C-0769-7-3 (Table 2).

Relationship of FHB ratings between greenhouse and field experiments

4 A significant correlation coefficient $(r=0.73, P<0.001)$ of mean PSS for 363 wheat accessions was observed between greenhouse and field experiments (Fig. 2), suggesting that most wheat accessions with a low PSS in the greenhouse usually had a low PSS in the field (Fig. 2, Table 2).

7 Correlation coefficients of PSS were significant ( $r=0.45$ to $0.64, P<0$.001) among the greenhouse experiments and among the field experiments. Significant correlations of PSS ratings were observed between three greenhouse and three field experiments, with $r$-values ranging from 0.40 to $0.96(P<0.001)$.

Comparing the resistant accessions identified from greenhouse and field experiments showed that 15 out of the $17 \mathrm{HWW}$ accessions that demonstrated resistance in greenhouse experiments also had resistance or moderate resistance in field experiments, including the accessions developed from institutions or companies in South Dakota (SD05085-1, SD05210, Lyman), Nebraska (Harry), Kansas (T154, Heyne, Everest, and AP05T2413), and the USDA showed low PSS in both greenhouse and field experiments (Table 2). Accessions with a low PSS in the field usually also showed a low PSS in greenhouse, with a few exceptions. consistent resistance to FHB. For example, all the Fhb1-carrying NILs of Wesley, two of the 
three Trego Fhb1 NILs, three of the four Clark Fhb1 NILs, and one of three Harding Fhb1 NILs showed consistent resistance in both environments (Table 2), suggesting that Fhb1 is a reliable

3 QTL for reduced PSS, and that it may contribute to both type I and type II resistance in the field.

4 However, several accessions that did not carry Fhb1 according to marker data also showed a

5 high level of resistance. For example, one HWW, T154, and two soft red wheats, Roane and

6 KY96C-0769-7-3, did not have Fhb1 according to the allele at Xumn10, but showed a high level

7 of resistance in all greenhouse and field experiments (Table 2). In addition, 35 accessions

8 without the Fhb1 resistance allele consistently showed moderate resistance in both greenhouse

9 and field environments (Table 2). Another 16 accessions lacking Fhb1, such as SD05085-1,

Heyne, Lyman, Everest, Harry, Hitch, Freedom, Bess, and Atlas66, had resistance or moderate

resistance in both greenhouse and field experiments (Table 2, Supplemental Table S1). These accessions can be used either as parents in further breeding crosses, or as FHB-resistant cultivars for commercial production to reduce FHB damage in epidemic years.

Discussion

\section{Repeatability of FHB resistance in field and greenhouse experiments}

Systematic evaluation of wheat germplasm for FHB resistance has been reported in China and many other countries (Snijders, 1990; Miller et al., 1998; Buerstmayr et al., 2003; Bai and Shaner, 2004; Zhang et al, 2008; Oliver et al., 2008), but not for U.S. HWW, especially elite HWW breeding lines, so this study is the first attempt to systematically evaluate FHB resistance in U.S. winter wheat (mainly HWW) cultivars and breeding lines in both greenhouse and field 
experiments. The results provide valuable information that breeders can use to select resistant parents for crosses or to select elite breeding lines that could be released as FHB-resistant cultivars or germplasm.

To evaluate FHB resistance accurately, an effective evaluation protocol is crucial. Needle inoculation of a single spikelet in a spike is a common practice used for type II resistance, and FHB severity usually is scored using either PSS per spike (Bai and Shaner, 2004) or a 1 to 10 visual scale (Stack and McMullen, 1995). Spraying spores over spikes or scattering Fusarium-infected wheat or corn spawn in field is used to evaluate both type I and type II resistance, and incidence is scored by estimating proportion of diseased spikes per experimental unit (plot) to estimate type I resistance (Stack and McMullen, 1995). In field experiments, it is often impossible to distinguish between type I and type II resistance, so an FHB index is often used to reflect overall resistance (Seem, 1984; Bai and Shaner, 2004; Paul et al., 2005).

In this study, the experimental materials were repeatedly evaluated for FHB resistance in both greenhouse and field experiments. In the greenhouse, needle inoculation was performed and type II resistance was measured. Among the three greenhouse experiments, the correlation coefficients were highly significant. In the field studies, plants were inoculated by a combination of both needle and spawn inoculations, and were misted hourly from heading to dough stages to ensure that there would be enough moisture for infection. This procedure significantly reduced disease difference caused due to plant heights and flowering times of different wheat accessions. In Manhattan, Kansas, spawn inoculation with misting usually is effective in most years for inducing sufficient infection of most plants with high repeatability (Bockus et al, 2007), but 
spring weather conditions vary from year to year, especially with regard to ambient temperature.

2 A warm early spring, for example, may lead to an early heading date, which may result in

3 infection escape in early maturing accessions due to lack of inoculum. The needle inoculation

4 technique can ensure that early flowering plants have an appropriate initial infection and can

5 minimize flowering time effect on FHB level. Also, we scored FHB based on flowering time (21

$6 \mathrm{~d}$ after needle inoculation), needle-inoculated plants were scored when natural infection was low

7 in these early flowering plants; thus, correlation coefficients among field experiments were

8 similar to those among greenhouse experiments. The combination of needle and spawn

9 inoculation methods can be recommended for field genetic studies, especially for genotypes with

10 large differences in flowering times. Although we observed a slight difference in resistance

11 ranking for some accessions between greenhouse and field experiments, the correlation

12 coefficients between greenhouse and field experiments were still very high (Fig. 2). This result

13 indicates that type II resistance is the major type of resistance for most accessions in field

14 conditions, with a few exceptions, such as in Husker, Century, P03207A1-7, KS08IFAFS1, and

IL02-18228 (Table 2 and Supplemental Table S1).

Husker, Century, and P03207A1-7 had a low PSS in the greenhouse experiments, indicating that they had type II resistance, but not type I resistance, as reflected by their high PSS in the field experiments, so they are not recommended for use in FHB resistance breeding. Only those accessions with low PSS in both field and greenhouse experiments should be used as resistant cultivars or breeding parents. 


\section{Impact of Fhb1 on FHB resistance}

2 To date, although many different sources of FHB resistance have been reported worldwide (Bai

3 and Shaner, 2004), the Fhb1 gene has shown the largest effect on type II resistance in diverse

4 genetic backgrounds and environments. Unfortunately, in this study, none of released cultivars

5 were shown to carry Fhb1, and only seven accessions (three HWW and four SWW) from

6 regional nurseries carried the Xumn10 marker allele associated with Fhb1-mediated resistance

7 (Liu et al., 2008). Among the seven accessions, NX03Y2489, VA05W-258, BC1007-7, and

8 NE08527 are unlikely to carry Fhb1 based on their pedigrees. One possible reason for the low

9 frequency of Fhb1 in U.S. winter wheat is that Sumai3 and its Chinese derivatives have many undesirable traits, so progenies with Fhb1 usually inherit some of these. When breeders select for desirable agronomic trait and adaptation to North America, plants carrying the Fhb1 gene might be discarded in field selection due to their poor agronomic traits. To solve this problem, the USDA Genotyping Laboratory in Manhattan, Kansas, successfully transferred Fhb1 into four U.S. winter wheat backgrounds (Wesley, Trego, Harding, and Clark) using marker-assisted backcrossing. This successfully combined Fhb1 with adapted agronomic traits and improved the resistance of U.S. winter wheat. Among the four recurrent parents, Clark is a soft red winter wheat, Trego is a hard white winter wheat, and Wesley and Harding are hard red winter wheats. In the greenhouse tests, four Wesley Fhb1 resistant NILs had a mean PSS similar to Sumai3. Three Trego Fhb1 resistant NILs and four Clark Fhb1 resistant NILs had a slightly higher PSS than Sumai3, but had a significant reduction in PSS compared with their recurrent parents. Significant PSS reduction in these NILs was also observed in the field experiments (Table 2 and 
1 Supplemental Table S1). These NILs have an appearance similar to their recurrent parents, so transfer of Fhb1 to U.S. winter wheat can quickly improve the level of FHB resistance. These selected Fhb1 NILs should be good parents for future breeding crosses; however, Fhb1 was not equally effective at enhancing FHB resistance in all genetic backgrounds. For example, the Harding Fhb1 NILs had a PSS similar to Harding. Thus, selecting appropriate recurrent parents is important for successful use of Fhb1.

Among potential Fhb1 carriers from the Regional Nurseries, INW0411, P02444A1-23-9, and P03112A1-7-14 displayed a high level of FHB resistance, whereas BC01007-7, VA05W-258, and NX03Y2489 were highly susceptible. NE08527 had only type II resistance, as shown in greenhouse experiments, but not in field experiments (Table 2). High susceptibility in some lines with the Fhb1 resistance-associated allele of the Xumn10 marker was possibly due to Xumn10 is not a diagnostic marker for Fhb1. This assumption is supported by two factors: 1) the pedigrees of those lines do not have any connection with Sumai3 sources, and 2) they all carry a susceptible allele that is associated with susceptibility or fail to amplify any PCR product at the Xsnp3BS-8 marker (Bernardo et al., 2012). All other lines with the Xumn10 allele linked to the Fhb1 gene have the allele associated with resistance at Xsnp3BS-8 (Table 2). Thus, Fhb1 as determined by both markers UMN10 and Xsnp3BS-8 significantly improved type II resistance in these U.S. wheat backgrounds.

\section{North American sources of FHB resistance in U.S. winter wheat}

In this study, 17 accessions showed a similar or slightly lower level of type II resistance than 
1 Sumai3 in the greenhouse experiments, even though they do not carry the Xumn10 marker allele associated with Fhb1 resistance allele and do not relate to any Chinese sources of resistance in their pedigrees. This suggested that the resistance of these accessions to FHB might originate from North American sources. Among them, seven accessions are SWW types. Freedom resistance in both field and greenhouse experiments. SD05210, Heyne, Lyman, Everest, and Harry also had relatively low PSS in both greenhouse and field experiments. These accessions are well-adapted to the Great Plains growing environments and are resistant to different diseases. Some of them have been released as commercial cultivars in the region, and thus are good native ideal parents for pyramiding Fhb1 with resistance QTLs from North American sources to attain 
'Aspen', U07-698-9, 'Endurance', N02Y5117, and HV9W02-942R in HWW, and IL00-8530, MD01W233-06-1, M04*5109, Ernie, OH02-12678, and KY97C-0519-04-07 in SWW (Table 2). These accessions had slightly higher PSS than previously mentioned highly resistant cultivars in both field and greenhouse experiments, but they were all moderately resistant, which means they could be important breeding parents for improvement of FHB resistance in U.S. winter wheat. 


\section{Reference}

Bai, G.H., and G.E. Shaner. 1994. Scab of wheat: prospects for control. Plant Dis. 78:760-766.

Bai, G.H., and G.E. Shaner. 2004. Management and resistance in wheat and barley to Fusarium head blight. Annu. Rev. Phytopathol. 42:135-161.

Bernardo, A.N., H.X. Ma, D.D. Zhang, and G.H. Bai. 2012. Single nucleotide polymorphism in wheat chromosome region harboring Fhb1 for Fusarium head blight resistance. Mol. Breed. 29:477-488.

Bockus, W.W., Z. Su, K.A. Garrett, B.S. Gill, J.P. Stack, A.K. Fritz, K.L. Roozeboom, and T.J. Martin. 2007. Number of experiments needed to determine wheat disease phenotypes for four wheat diseases. Plant Dis. 91:103-108.

Buerstmayr, H., M. Stierschneider, B. Steiner, M. Lemmens, M. Griesser, E. Nevo, and T. Fahima. 2003. Variation for resistance to head blight caused by Fusarium graminearum in wild emmer (Triticum dicoccoides) originating from Israel. Euphytica. 130:17-23.

Buerstmayr, H., T. Ban, and J.A. Anderson. 2009. QTL mapping and marker-assisted selection for Fusarium head blight resistance in wheat: a review. Plant Breed. 128:1-26.

Gooding, R.W., H.N. Lafever, K.G. Campbell, and L.D. Herald. 1997. Registration of ‘Freedom’ wheat. Crop Sci. 37:1007.

Griffey, C.A., T.M. Starling, A.M. Price, W.L. Sisson, M.K. Das, T.H. Pridgen, M.E. Vaughn, W.L. Rohrer, and D.E. Brann. 2001. Registration of 'Roane’ wheat. Crop Sci. 41:1359.

Liu, S., Z.A. Abate, and A.L. McKendry. 2005. Inheritance of Fusarium head blight resistance in the soft red winter wheat Ernie. Theor. Appl. Genet. 110:454-461.

Liu, S.X., M.O. Pumphrey, B.S. Gill, H.N. Trick, J.L. Zhang, J. Dolezel, B. Chalhoub, and J.A. Anderson. 2008. Toward positional cloning of FHB1, a major QTL for Fusarium head blight resistance in wheat. Cereal Res. Comm. 36:195-201.

Liu, S.Y., M.D. Hall, C.A. Griffey, and A.L. McKendry. 2009. Meta-analysis of QTL associated with Fusarium head blight resistance in wheat. Crop Sci. 49:1955-1968.

Ma, H.X., K.M. Zhang, L. Gao, G.H. Bai, H.G. Chen, Z.X. Cai, and W.Z. Lu. 2006. Quantitative trait loci for resistance to Fusarium head blight and deoxynivalenol accumulation in 

Wangshuibai wheat under field conditions. Plant Pathol. 55:739-745.

McKendry, A.L., J.E. Berg, D.N. Tague, and K.D. Kephart. 1995. Registration of 'Ernie’ wheat. Crop Sci. 35:1513.

Mesterházy, A. 1995. Types and components of resistance of resistance to Fusarium head blight of wheat. Plant Breed. 114:377-386.

Miller, J.D., R.W. Stack, and L.R. Joppa. 1998. Evaluation of Triticum turgidum L. var. dicoccoides for resistance to Fusarium head blight and stem rust. p. 292-293. In A.E. Slinkard (ed.) Proc. 9th Int. Wheat Genetics Symp. III, Saskatoon, SK. 2-7 Aug. 1998. Univ. of Saskatchewan Ext. Press, Saskatoon.

Oliver, R.E., X. Cai, T.L. Friesen, S. Halley, R.W. Stack, and S.S. Xu. 2008. Evaluation of Fusarium head blight resistance in tetraploid wheat (Tritium turgidum L.). Crop Sci. 48:213-222.

Osborne, L.E., and J.M. Stein. 2007. Epidemiology of Fusarium head blight on small-grain cereals. Int. J. Food Microbiol. 119:103-108.

Parry, D.W., P. Jenkinson, and L. McLeod. 1995. Fusarium ear blight (scab) in small grain cereals, a review. Plant Pathol. 44:207-238.

Paul, P.A., S.M. El-Allaf, P.E. Lipps, and L.V. Madden. 2005. Relationships between incidence and severity of Fusarium head blight on winter wheat in Ohio. Phytopathology. 95: 1049-1060.

Rudd, J.C., R.D. Horsley, A.L. McKendry, and E.M. Elias. 2001. Host plant resistance genes for Fusarium head blight: sources, mechanisms, and utility in conventional breeding systems. Crop Sci. 41(3):620-627.

Schroeder, H.W., and J.J. Christensen. 1963. Factors affecting resistance of wheat to scab caused by Gibberella zeae. Phytopathology. 53:831-838.

Seem, R.C. 1984. Disease incidence and severity relationships. Ann. Rev. Phytopathol. 22:13350.

Snijders, C.H.A. 1990. Genetic variation for resistance to Fusarium head blight in bread wheat. 
2 Stack, R.W., and M.P. McMullen. 1995. A visual scale to estimate severity of Fusarium head 3 blight in wheat. Plant Pathol. 1095.

4 Sun, X.C., W. Bockus, and G.H. Bai. 2010. Quantitative trait loci for resistance to Pyrenophora

Yu, J.B., G.H. Bai, W.C. Zhou, Y.H. Dong, and F.L. Kolb. 2008. Quantitative trait loci for

7 Fusarium head blight resistance in a recombinant inbred population of 8 Wangshuibai/Wheaton. Phytopathology. 98:87-94.

9 Zhang, J.X., Y. Jin, J.C. Rudd, and H.E. Bockelman. 2008. New Fusarium head blight resistant

12 Zhang, X.H., G.H. Bai, W. Bockus, X.J. Ji, and H.Y. Pan. 2012. Quantitative trait loci for Fusarium head blight resistance in U.S. hard winter wheat cultivar Heyne. Crop Sci. 52:1187-1194.

15

16

17 


\section{Figures}

2

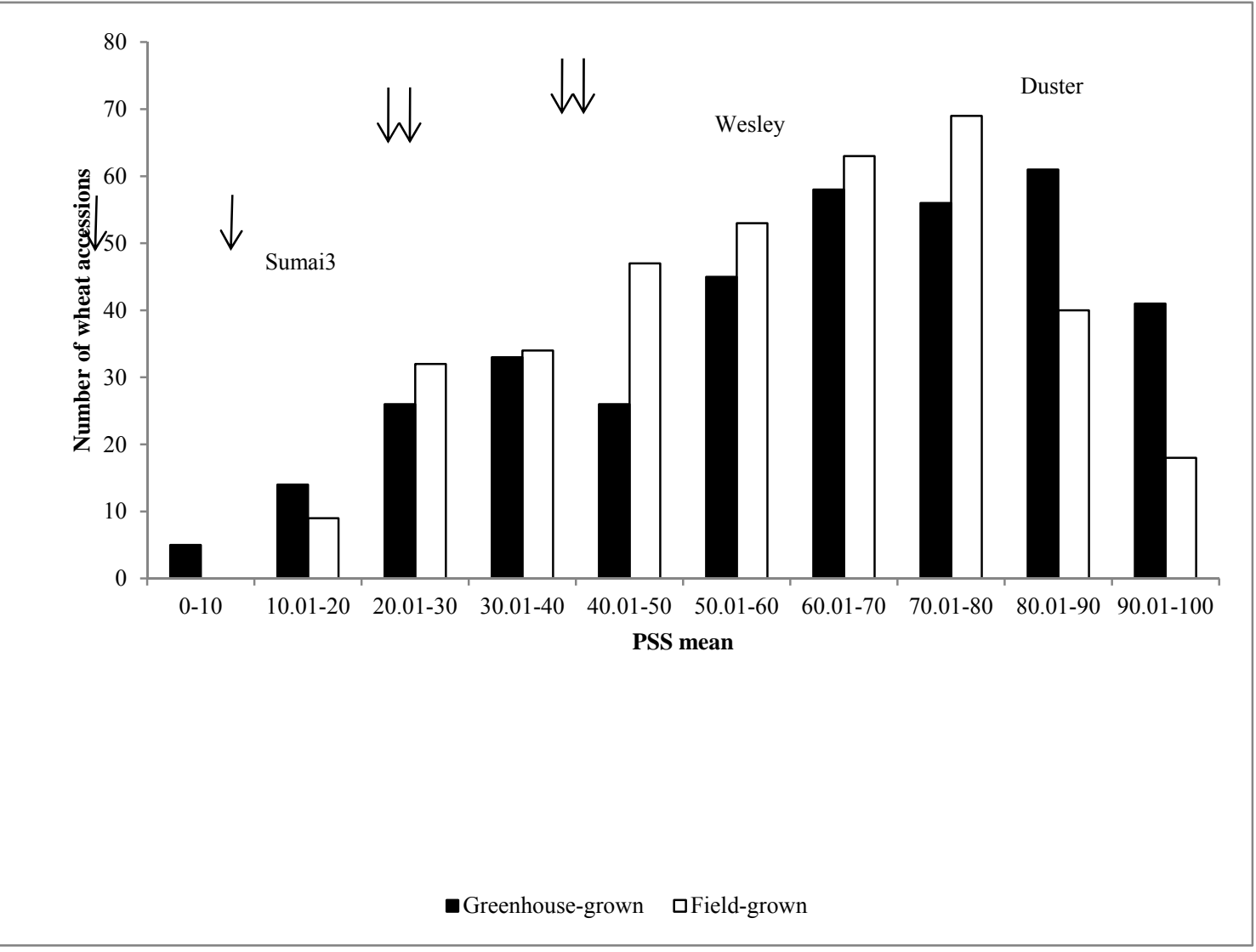

4

5 Figure 1. Frequency distribution of mean percentage of symptomatic spikelets (PSS) in a spike 6 for 363 wheat accessions evaluated in greenhouse and field experiments at Manhattan, KS. 


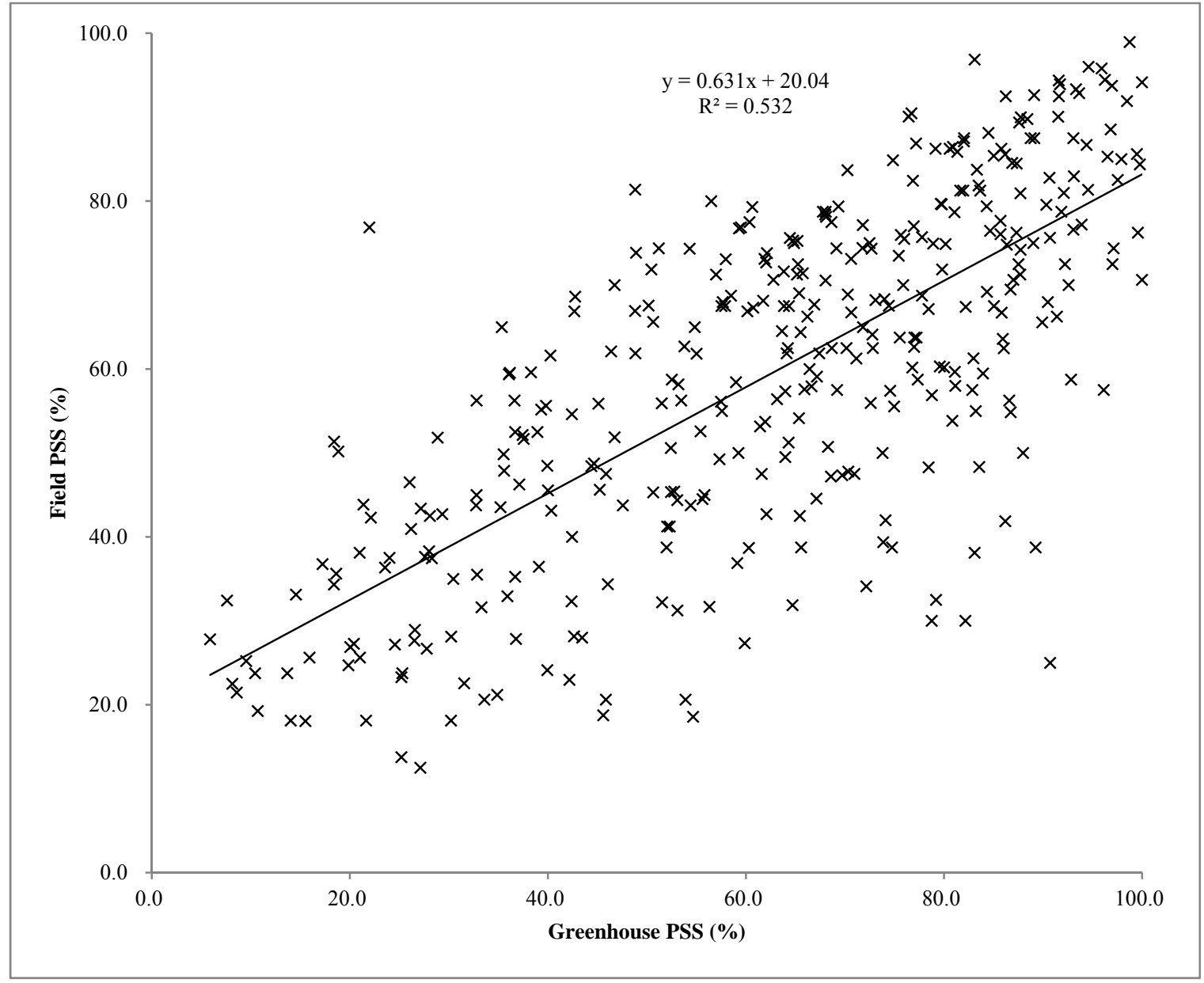

3

4 Figure 2. Correlation of percentages of symptomatic spikelets in a spike (PSS) of 363 U.S.

5 winter wheat accessions between greenhouse and field experiments conducted in Manhattan, KS. 
1 Table 1. Reactions of two classes of U.S. winter wheat accessions, hard winter wheat (HWW) and soft winter wheat (SWW), to Fusarium 2 head blight inoculation in the greenhouse and field experiments.

\begin{tabular}{|c|c|c|c|c|c|c|c|c|c|c|}
\hline \multirow[b]{2}{*}{$\begin{array}{l}\text { Wheat } \\
\text { Class }\end{array}$} & \multicolumn{5}{|c|}{ No. of accessions in greenhouse ${ }^{\dagger}$} & \multicolumn{5}{|c|}{ No. of accessions in field ${ }^{\dagger}$} \\
\hline & $\begin{array}{c}\mathrm{R} \\
(\leq 23.0 \%)\end{array}$ & $\begin{array}{c}\text { MR } \\
(23.1 \%-45.0 \%)\end{array}$ & $\begin{array}{c}\text { MS } \\
(45.1 \%-70.0 \%)\end{array}$ & $\begin{array}{c}\mathrm{S} \\
(\geq 70.1 \%)\end{array}$ & Total & $\begin{array}{c}\mathrm{R} \\
(\leq 25.0 \%)\end{array}$ & $\begin{array}{c}\text { MR } \\
(25.1 \%-50.0 \%)\end{array}$ & $\begin{array}{c}\text { MS } \\
(50.1 \%-75.0 \%)\end{array}$ & $\begin{array}{c}\text { S } \\
(\geq 75.1)\end{array}$ & Total \\
\hline HWW & 17 & 40 & 97 & 135 & 289 & 10 & 75 & 125 & 79 & 289 \\
\hline SRWW & 8 & 24 & 19 & 23 & 74 & 12 & 23 & 26 & 13 & 74 \\
\hline Total & 25 & 64 & 116 & 158 & 363 & 22 & 98 & 151 & 92 & 363 \\
\hline
\end{tabular}

3 Phenotypic classification of accessions in greenhouse and field based on their reactions to F. graminearum by comparing their mean 4 percentage of symptomatic spikelets (PSS) in a spike and 95\% confidence intervals with resistant (R) control (Sumai3), moderately 5 susceptible (MS) control (Wesley) and susceptible (S) control (Duster). Moderately resistant (MR) refers to accessions that had PSS 6 between Sumai3 and Wesley. 
1 Table 2. A list of accessions that showed resistance and moderate resistance to Fusarium head blight as reflected by mean percentage of symptomatic spikelets (PSS) in a spike evaluated in greenhouse (GH) and field (F) experiments in Manhattan, KS and that carry

$3 \quad$ Fhb1 marker allele associated with FHB resistance.

\begin{tabular}{|c|c|c|c|c|c|}
\hline Accession & Class & PSS GH & PSS (F) & Xumn10 & $\mathrm{SNP}^{\S}$ \\
\hline \multicolumn{6}{|c|}{ Wheat accessions with Fhb1 allele } \\
\hline INW0411 & SWW & $5.9 \pm 2.6$ & $27.8 \pm 32.8$ & + & $\mathrm{G}$ \\
\hline WesleyFhb1NIL09S-103 ${ }^{\dagger}$ & HWW & $8.1 \pm 3.4$ & $22.5 \pm 8.9$ & + & G \\
\hline WesleyFhb1NIL09S-104 ${ }^{\dagger}$ & HWW & $10.4 \pm 2.8$ & $23.8 \pm 5.9$ & + & G \\
\hline $\mathrm{KS} 08 \mathrm{FHB}-78^{\dagger}$ & HWW & $13.7 \pm 8.4$ & $23.8 \pm 11.8$ & + & G \\
\hline Wesley FHB $1^{\dagger}$ & HWW & $14.0 \pm 6.1$ & $18.1 \pm 4.7$ & + & G \\
\hline WesleyFhb1NIL09S-105 ${ }^{\dagger}$ & HWW & $15.9 \pm 7.6$ & $25.6 \pm 9.2$ & + & G \\
\hline TregoFhb1NIL09S-98 ${ }^{\dagger}$ & HWW & $21.0 \pm 5.5$ & $25.6 \pm 10.3$ & + & G \\
\hline TregoFhb1NIL09S-99 ${ }^{\dagger}$ & HWW & $21.6 \pm 9.4$ & $18.1 \pm 3.4$ & + & G \\
\hline ClarkFhb1NIL-75 ${ }^{\dagger}$ & SWW & $26.7 \pm 7.1$ & $13.8 \pm 2.5$ & + & G \\
\hline ClarkFhb1NIL09F-23 ${ }^{\dagger}$ & SWW & $27.1 \pm 3.3$ & $12.5 \pm 2.7$ & + & G \\
\hline ClarkFhb1NIL09F-45 ${ }^{\dagger}$ & SWW & $30.2 \pm 21.0$ & $18.1 \pm 5.1$ & + & G \\
\hline $\mathrm{KS} 08 \mathrm{FHB}-31^{\dagger}$ & HWW & $33.6 \pm 21.1$ & $20.6 \pm 4.1$ & + & G \\
\hline P02444A1-23-9 & SWW & $34.9 \pm 30.4$ & $21.2 \pm 14.7$ & + & G \\
\hline NE08527 & HWW & $35.3 \pm 15.1$ & $65.0 \pm 11.2$ & + & $\mathrm{C}$ \\
\hline P03112A1-7-14 & SWW & $35.6 \pm 30.4$ & $47.9 \pm 24.8$ & + & $\mathrm{G}$ \\
\hline HardingFhb1NIL09S-107 ${ }^{\dagger}$ & HWW & $44.7 \pm 18.9$ & $48.8 \pm 9.5$ & + & G \\
\hline TregoFhb1NIL09S-100 ${ }^{\dagger}$ & HWW & $45.6 \pm 10.8$ & $18.8 \pm 5.9$ & + & G \\
\hline $\mathrm{BC} 01007-7$ & HWW & $52.5 \pm 19.2$ & $58.8 \pm 6.8$ & + & $\mathrm{N}$ \\
\hline ClarkFhb1NIL09F-4 ${ }^{\dagger}$ & SWW & $53.9 \pm 14.8$ & $20.6 \pm 9.2$ & + & G \\
\hline HardingFhb1NIL09S-109 ${ }^{\dagger}$ & HWW & $59.1 \pm 18.5$ & $36.9 \pm 15.6$ & + & $\mathrm{G}$ \\
\hline HardingFhb1NIL09S-108 ${ }^{\dagger}$ & HWW & $64.7 \pm 11.0$ & $31.9 \pm 12.6$ & + & $\mathrm{G}$ \\
\hline VA05W-258 & SWW & $68.3 \pm 10.2$ & $50.7 \pm 20.3$ & + & $\mathrm{C}$ \\
\hline NX03Y2489 & HWW & $93.7 \pm 10.7$ & $92.9 \pm 9.9$ & + & $\mathrm{N}$ \\
\hline
\end{tabular}




Freedom
MO040152
Roane
SD05085-1
T154
Bess
SD05210
Century
Heyne
P03207A1-7
KY96C-0769-7-3
Lyman
Everest
Harry
Atlas66
Husker
AP05T2413
Mean PSS (\%)

Resistant accessions without Fhb1 allele in greenhouse experiments

Additional accessions without Fhb1 but with FHB resistance in field experiments

IL02-18228
M03-3616-C
G41732
USG 3555
Hitch
G61505
KS08IFAFS1

SWW

SWW

SWW

SWW

HWW

SWW

HWW

$\begin{array}{rr}7.6 \pm 3.0 & 32.4 \pm 25.2 \\ 9.5 \pm 1.7 & 25.2 \pm 14.2 \\ 10.7 \pm 4.8 & 19.3 \pm 7.4 \\ 14.6 \pm 5.8 & 33.1 \pm 11.6 \\ 15.5 \pm 7.8 & 18.1 \pm 6.5 \\ 17.2 \pm 14.4 & 36.8 \pm 28.2 \\ 18.4 \pm 10.9 & 34.3 \pm 20.1 \\ 18.4 \pm 9.6 & 51.4 \pm 23.2 \\ 18.6 \pm 15.4 & 35.6 \pm 7.4 \\ 18.8 \pm 12.3 & 50.2 \pm 26.7 \\ 19.9 \pm 11.1 & 24.7 \pm 7.9 \\ 20.0 \pm 8.8 & 26.9 \pm 6.2 \\ 20.4 \pm 12.5 & 27.3 \pm 14.5 \\ 21.0 \pm 13.0 & 38.1 \pm 5.4 \\ 21.4 \pm 13.4 & 43.9 \pm 13.9 \\ 22.0 \pm 14.9 & 76.9 \pm 11.3 \\ 22.1 \pm 12.3 & 42.3 \pm 25.3 \\ 17.4 \pm 4.3 & 36.3 \pm 13.8\end{array}$

$54.7 \pm 27.5 \quad 18.6 \pm 10.2$

$31.5 \pm 17.1 \quad 22.6 \pm 9.0$

$42.2 \pm 27.1 \quad 23.0 \pm 11.7$

$25.2 \pm 13.7 \quad 23.3 \pm 12.4$

$25.3 \pm 15.3 \quad 23.8 \pm 4.6$

$39.9 \pm 33.6 \quad 24.1 \pm 8.8$

$90.7 \pm 4.0 \quad 25.0 \pm 7.2$ 


IL00-8530
SD08198
MD01W233-06-1
NI04420
SD05118
T153
M04*5109
MTS0531
G69202
Ernie
CO04W210
2008-193 Jagger (FHB3)
OK05128
OK05134
Aspen
OH02-12678
NE06545
Camelot
OH02-7217
U07-698-9
MD99W483-06-9
OK05723W
KY97C-0519-04-07
P04287A1-10
Endurance
Winterhawk
N02Y5117

\section{Moderately resistant accessions without $F$ hb1 in greenhouse and field}

$\begin{array}{lrrrr}\text { SWW } & 23.6 \pm 15.6 & 36.4 \pm 19.5 & - & - \\ \text { HWW } & 24.0 \pm 9.8 & 37.5 \pm 8.9 & - & - \\ \text { SWW } & 24.6 \pm 17.9 & 27.2 \pm 10.7 & - & - \\ \text { HWW } & 26.0 \pm 21.7 & 46.5 \pm 10.9 & - & - \\ \text { HWW } & 26.2 \pm 22.4 & 40.9 \pm 26.9 & - & - \\ \text { HWW } & 26.5 \pm 9.8 & 27.7 \pm 7.9 & - & - \\ \text { SWW } & 26.6 \pm 23.6 & 28.9 \pm 8.2 & - & - \\ \text { HWW } & 27.2 \pm 11.9 & 43.4 \pm 19.9 & - & - \\ \text { SWW } & 27.6 \pm 30.4 & 37.6 \pm 26.4 & - & - \\ \text { SWW } & 27.8 \pm 14.0 & 26.7 \pm 14.3 & - & - \\ \text { HWW } & 28.0 \pm 12.0 & 38.3 \pm 13.7 & - & - \\ \text { HWW } & 28.1 \pm 6.4 & 42.5 \pm 12.7 & - & - \\ \text { HWW } & 28.3 \pm 12.4 & 37.4 \pm 11.0 & - & - \\ \text { HWW } & 29.3 \pm 17.6 & 42.7 \pm 16.5 & - & - \\ \text { HWW } & 30.2 \pm 11.6 & 28.1 \pm 6.8 & - & - \\ \text { SWW } & 30.5 \pm 14.8 & 35.0 \pm 14.9 & - & - \\ \text { HWW } & 32.8 \pm 16.9 & 43.8 \pm 13.8 & - & - \\ \text { HWW } & 32.8 \pm 18.2 & 45.0 \pm 9.7 & - & - \\ \text { SWW } & 32.8 \pm 7.7 & 35.5 \pm 10.7 & - & - \\ \text { HWW } & 33.3 \pm 15.9 & 31.6 \pm 20.6 & - & - \\ \text { SWW } & 35.2 \pm 18.8 & 43.5 \pm 16.9 & - & - \\ \text { HWW } & 35.5 \pm 25.7 & 49.8 \pm 25.9 & - & - \\ \text { SWW } & 35.9 \pm 27.2 & 32.9 \pm 9.4 & - & - \\ \text { SWW } & 36.7 \pm 15.8 & 35.2 \pm 4.6 & - & - \\ \text { HWW } & 36.8 \pm 22.2 & 27.9 \pm 9.4 & - & - \\ \text { HWW } & 37.1 \pm 11.2 & 46.3 \pm 8.1 & - & - \\ \text { HWW } & 39.1 \pm 27.4 & 36.4 \pm 20.1 & - & -\end{array}$




\begin{tabular}{|c|c|c|c|c|c|}
\hline OK06528 & HWW & $39.9 \pm 34.1$ & $48.5 \pm 23.8$ & - & - \\
\hline NW05M6011-6-1 & HWW & $40.0 \pm 22.9$ & $45.5 \pm 5.5$ & - & - \\
\hline Arapahoe & HWW & $40.3 \pm 14.5$ & $43.1 \pm 6.4$ & - & - \\
\hline M04-4715 & SWW & $42.4 \pm 29.2$ & $32.3 \pm 12.4$ & - & - \\
\hline Overland & HWW & $42.4 \pm 19.9$ & $40.0 \pm 15.6$ & - & - \\
\hline HV9W02-942R & HWW & $42.6 \pm 18.2$ & $28.2 \pm 11.2$ & - & - \\
\hline MO011126 & SWW & $43.5 \pm 15.5$ & $28.0 \pm 13.5$ & - & - \\
\hline Jerry & HWW & $44.4 \pm 18.9$ & $48.4 \pm 17.7$ & - & - \\
\hline \multicolumn{6}{|l|}{ Control cultivars } \\
\hline Sumai3 & SWW & $8.6 \pm 3.6$ & $21.5 \pm 18.0$ & - & G \\
\hline Wesley & HWW & $51.5 \pm 22.2$ & $55.9 \pm 18.0$ & - & - \\
\hline Duster & HWW & $81.3 \pm 18.7$ & $85.9 \pm 8.3$ & - & - \\
\hline
\end{tabular}

1 Hard and soft winter wheat Fhb1 near-isogenic lines (NILs).

2 Mean of standard deviation.

3 \& In Xumn10, '+' refers as Fhb1 allele associated with FHB resistance, and '-' refers as non-Fhb1 associated with FHB susceptibility; In single nucleotide polymorphism (SNP) marker data derived from Xsnp3BS-8, G refers as Fhb1 allele associated with FHB resistance, C refers as non-Fhb1 associated with FHB susceptibility, and $\mathrm{N}$ refers as no polymerase chain reaction products in these lines carrying 6 Fhb1 resistant allele as predicted by Xumn10. '-' means that this marker was not analyzed for these lines without the resistance allele as 7 predicted by Xumn10. 
1 Supplemental Table S1.Wheat accessions resistance to Fusarium head blight in greenhouse and field experiments.

\begin{tabular}{|c|c|c|c|c|c|}
\hline Accession & Type $^{\ddagger}$ & Sources $\S$ & Pedigree & $\begin{array}{l}\text { Greenhouse PSS (\%) } \\
\text { ? }\end{array}$ & Field PSS (\%) \\
\hline WesleyFhb1NIL09S-103 & HWW & HWWGRU & ND2928/Wesley*3 F6 & $8.1 \pm 3.4$ & $22.5 \pm 8.9$ \\
\hline WesleyFhb1NIL09S-104 & HWW & HWWGRU & ND2928/Wesley*3 F6 & $10.4 \pm 2.8$ & $23.8 \pm 5.9$ \\
\hline KS08FHB-78 & HWW & Tri-state FHB Nursery & Bulk Selection & $13.7 \pm 8.5$ & $23.8 \pm 11.8$ \\
\hline Wesley FHB1 & HWW & HWWGRU & ND2928/Wesley*3 F6 & $14.0 \pm 6.1$ & $18.1 \pm 4.7$ \\
\hline SD05085-1 & HWW & Tri-state FHB Nursery & SD92107-2/TX96D2845 & $14.6 \pm 5.8$ & $33.1 \pm 11.6$ \\
\hline $\mathrm{T} 154^{\dagger}$ & HWW & 2008 SRPN & T88/2180//T811 & $15.5 \pm 7.8$ & $18.1 \pm 6.5$ \\
\hline WesleyFhb1NIL09S-105 & HWW & HWWGRU & ND2928/Wesley*3 F6 & $15.9 \pm 7.6$ & $25.6 \pm 9.2$ \\
\hline SD05210 & HWW & 2008 NRPN & SD98444/SD97060 & $18.4 \pm 10.9$ & $34.3 \pm 20.1$ \\
\hline Century & HWW & PI 502912 & Payne//TAM W-101/Amigo & $18.4 \pm 9.6$ & $51.4 \pm 23.2$ \\
\hline Lyman & HWW & South Dakota State University & KS93U134/Arapahoe & $20.0 \pm 8.8$ & $26.9 \pm 6.2$ \\
\hline Everest $^{\dagger}$ & HWW & 2008 SRPN & HBK1064-3/Betty 'S’//VBF0589-1/IL89-6483 & $20.4 \pm 12.5$ & $27.3 \pm 14.5$ \\
\hline Harry & HWW & PI 632435 & NE90614/NE87612 198/Lancer/3/Newton/Brule & $21.0 \pm 13.0$ & $38.1 \pm 5.4$ \\
\hline Husker & HWW & Tri-state FHB Nursery & NE96644//Pavon/*3 SCOUT66/3/Wahoo (sib)/4/Wesley & $22.0 \pm 14.9$ & $76.9 \pm 11.3$ \\
\hline AP05T2413 & HWW & 2008 SRPN & (KS95U522/TX95VA0011)F1/Jagger & $22.1 \pm 12.3$ & $42.3 \pm 25.3$ \\
\hline SD08198 & HWW & Tri-state FHB Nursery & Wesley/NE93613 & $24.0 \pm 9.8$ & $37.5 \pm 8.9$ \\
\hline Hitch & HWW & WestBred LLC. & Unknown & $25.3 \pm 15.3$ & $23.8 \pm 4.6$ \\
\hline NI04420 & HWW & 2008 NRPN & NE96644//PAVON/*3Scout 66/3/Wahoo sib & $26.0 \pm 21.7$ & $46.5 \pm 10.9$ \\
\hline SD05118 & HWW & 2008 NRPN & Wesley/NE93613 & $26.2 \pm 22.4$ & $40.9 \pm 26.9$ \\
\hline $\mathrm{T} 153 \dagger$ & HWW & 2008 SRPN & T136/T151 & $26.5 \pm 9.8$ & $27.7 \pm 7.9$ \\
\hline MTS0531 & HWW & 2008 NRPN & L'Govskaya 167/Rampart/MT9409 (solid stem) & $27.2 \pm 11.9$ & $43.4 \pm 19.9$ \\
\hline 2008-193 Jagger (FHB3) & HWW & Oklahoma State University & Jagger-Leymus racemosus 7 A translocation & $28.1 \pm 6.4$ & $42.5 \pm 12.7$ \\
\hline OK05128 & HWW & Oklahoma State University & KS94U275/OK94P549 F4:10 RC & $28.3 \pm 12.4$ & $37.4 \pm 11.0$ \\
\hline KS980512-2-2 & HWW & 2008 SRPN & T67/X84W063-9-45//K92/3/SNF/4/X86509-1-1/X84W063-9-39-2//K92 & $28.9 \pm 14.5$ & $51.8 \pm 13.6$ \\
\hline OK05134 & HWW & Oklahoma State University & OK97411/TX91D6825 F4:10 & $29.3 \pm 17.6$ & $42.7 \pm 16.5$ \\
\hline NE06545 & HWW & 2010 SRPN & KS92-946-B-15-1/Alliance & $32.8 \pm 16.9$ & $43.8 \pm 13.8$ \\
\hline Camelot & HWW & University of Nebraska & KS91H184/Arlin sib//KS91HW29/3/NE91631/4/VBF0168 & $32.8 \pm 18.2$ & $45.0 \pm 9.7$ \\
\hline Bill Brown & HWW & Colorado State University & Yumar/Arlin & $32.8 \pm 10.7$ & $56.3 \pm 3.5$ \\
\hline U07-698-9 ${ }^{\dagger}$ & HWW & 2008 RGON & Jagger*2/HD29 & $33.3 \pm 15.9$ & $31.6 \pm 20.6$ \\
\hline
\end{tabular}




\begin{tabular}{|c|c|c|c|c|c|}
\hline KS08FHB-31 & HWW & Tri-state FHB Nursery & Bulk Selection & $33.6 \pm 21.1$ & $20.6 \pm 4.1$ \\
\hline NE08527 & HWW & Tri-state FHB Nursery & 1998 Roane/Culver & $35.3 \pm 15.1$ & $65.0 \pm 11.2$ \\
\hline OK05723W & HWW & Oklahoma State University & SWM866442/Betty F4:10 HW & $35.5 \pm 25.7$ & $49.8 \pm 25.9$ \\
\hline KS020822-M-5 & HWW & Tri-state FHB Nursery & KS950409-P-4/KS940786-17-3//KS920709-B-5-2-2 & $36.1 \pm 6.3$ & $59.4 \pm 6.4$ \\
\hline Centerfield & HWW & Oklahoma State University & TAM $110 / 2174 * 2$ & $36.2 \pm 25.7$ & $59.6 \pm 21.8$ \\
\hline SD06156-1 & HWW & Tri-state FHB Nursery & Wesley/Falcon & $36.6 \pm 15.7$ & $56.3 \pm 9.3$ \\
\hline OK06336 & HWW & Oklahoma State University & Magvars/2174//Enhancer F4:9 & $36.7 \pm 13.8$ & $52.5 \pm 24.0$ \\
\hline Endurance $^{\dagger}$ & HWW & Oklahoma State University & HBY756A/Siouxland//2180 & $36.8 \pm 22.2$ & $27.9 \pm 9.4$ \\
\hline Winterhawk & HWW & WestBred LLC. & Unknown & $37.1 \pm 11.2$ & $46.3 \pm 8.1$ \\
\hline NE07444 & HWW & 2010 SRPN & KS96HW10-3/Wahoo/NE99585 & $38.9 \pm 15.3$ & $52.5 \pm 6.6$ \\
\hline N02Y5117 & HWW & 2008 RGON & Yuma//T-57/3/CO850034/4/4*Yuma/5/KS91H184/Arlin S/KS91HW29//NE89526 & $39.1 \pm 27.4$ & $36.4 \pm 20.1$ \\
\hline TX06A001376 & HWW & 2008 RGON & NE94482/TX95A1161 & $39.3 \pm 29.1$ & $55.2 \pm 16.7$ \\
\hline OK06528 & HWW & Oklahoma State University & Vilma/Hickok//Heyne F4:9 A & $39.9 \pm 34.1$ & $48.5 \pm 23.8$ \\
\hline OK06313 & HWW & Oklahoma State University & Emma/Karl 92//2174 F4:9 & $40.3 \pm 25.7$ & $61.6 \pm 12.9$ \\
\hline Arapahoe & HWW & PI 518591 & Brule/3/Parker*4/Agent//Belocerkovskaja 198/Lancer & $40.3 \pm 14.5$ & $43.1 \pm 6.4$ \\
\hline SD06069 $9^{\dagger}$ & HWW & 2008 NRPN & Harry/Wesley//Jerry & $42.4 \pm 19.2$ & $54.6 \pm 16.2$ \\
\hline Overland & HWW & 2010 NRPN & Millennium sib//ND8974 & $42.4 \pm 19.9$ & $40.0 \pm 15.6$ \\
\hline HV9W02-942R ${ }^{\dagger}$ & HWW & 2008 SRPN & 53/3/Abl/1113//K92/4/Jag/5/KS89180B & $42.6 \pm 18.2$ & $28.2 \pm 11.2$ \\
\hline SD07165 & HWW & Tri-state FHB Nursery & SD97250/SD99W006//Avalanche & $42.7 \pm 11.9$ & $66.9 \pm 14.8$ \\
\hline Jerry $^{\dagger}$ & HWW & PI 632433 & Roughrider//Winoka/NB66425/3/Arapahoe & $44.4 \pm 18.9$ & $48.4 \pm 17.7$ \\
\hline HardingFhb1NIL09S-107 & HWW & HWWGRU & Sumai3/Harding*3 F4 & $44.7 \pm 18.9$ & $48.8 \pm 9.5$ \\
\hline KS970187-1-10 & HWW & 2008 SRPN & TAM107*2/TA759//HBC197F-1/3/2145 & $45.2 \pm 11.1$ & $45.6 \pm 16.1$ \\
\hline 2174 & HWW & HWWGRU & IL71-5662, VA66-54-10, Arthur, PL145, NB34, Scout, Sturdy, MoW7510 & $45.9 \pm 28.1$ & $47.5 \pm 5.0$ \\
\hline Millennium & HWW & University of Nebraska & Arapahoe/Abilene/4/Colt/3/Warrior *5/Agent//Kavkaz & $46.0 \pm 11.1$ & $34.4 \pm 8.0$ \\
\hline KS010143K-11 & HWW & 2008 RGON & TAM-400/KS950301-DD-4 & $46.4 \pm 26.7$ & $62.1 \pm 23.9$ \\
\hline OK07231 & HWW & 2010 SRPN & OK92P577-(RMH 3099)/OK93P656-(RMH 3299) F4:10 & $46.7 \pm 11.7$ & $70.0 \pm 8.2$ \\
\hline ART & HWW & AgriPro Seeds Inc. & Jagger related & $47.6 \pm 18.3$ & $43.8 \pm 14.7$ \\
\hline MTS0713 & HWW & 2010 NRPN & 93X312E14/NuHorizon & $48.8 \pm 29.3$ & $61.9 \pm 16.7$ \\
\hline OK02522W & HWW & Oklahoma State University & KS96WGRC39/Jagger & $48.9 \pm 25.5$ & $73.8 \pm 21.9$ \\
\hline OK06319 & HWW & Oklahoma State University & Enhancer/2174 F4:9 & $50.2 \pm 24.5$ & $67.6 \pm 16.2$ \\
\hline SD07W053 & HWW & Tri-state FHB Nursery & Wendy/SD00W073//KS01HW54-4 & $50.5 \pm 28.8$ & $71.9 \pm 16.1$ \\
\hline
\end{tabular}




\begin{tabular}{|c|c|c|c|}
\hline KS020947-K-13 & HWW & Tri-state FHB Nursery & 01ROMIG-9/Jagger//KS940786-17-3 \\
\hline Wesley $^{\dagger}$ & HWW & PI 605742 & KS831936-3/NE86501//Colt/Cody \\
\hline SD07220 $0^{\dagger}$ & HWW & 2008 RGON & Tandem/Goodstreak \\
\hline KS031027-FHB $\sim 8$ & HWW & Tri-state FHB Nursery & MN99112/KS970226-5-4//KS970104-3-13 \\
\hline CA9W08-856 & HWW & 2010 NRPN & Jerry/CDC Falcon \\
\hline Harding & HWW & HWWGRU & Brule//Bennett/Chisholm/3/Arapahoe \\
\hline BC01007-7 & HWW & 2010 NRPN & W99-331/97x0906-8 \\
\hline NE02533 & HWW & 2008 NRPN & NE94458/Jagger \\
\hline Hondo & HWW & Tri-state FHB Nursery & Unknown \\
\hline Shocker & HWW & AGSECO & Unknown \\
\hline NE07627 & HWW & 2010 NRPN & KS96HW10-3/Wahoo//NE99585 \\
\hline NE06430 & HWW & Tri-state FHB Nursery & Wesley (N95L158)/3/KS9U241//Ike/TXGH12388-120*4/FS2 \\
\hline Kharkof ${ }^{\dagger}$ & HWW & $\underline{\text { PI } 5641}$ & Unknown \\
\hline NE06619 & HWW & 2008 RGON & Wesley/Wahoo \\
\hline TXHT001F8-CS06/325-PRE07/75 & HWW & 2008 RGON & TX01M5009/Halberd \\
\hline $09-25-11$ rec-124 & HWW & Kansas State University & CS-Leymus racemosus 7A translocation \\
\hline BZ9W05-2039 & HWW & 2010 NRPN & Vanguard/BZ9W96-895 \\
\hline $\mathrm{CO} 04499$ & HWW & 2010 SRPN & Above/Stanton \\
\hline NE06469 & HWW & 2010 NRPN & Unknown \\
\hline OK05312 & HWW & 2008 RGON & TX93V5919/WGRC40//OK94P549/WGRC34 \\
\hline Hawken & HWW & AgriPro Seed Inc. & Unknown \\
\hline SD06158 & HWW & Tri-state FHB Nursery & Wesley/Falcon \\
\hline NE05569 & HWW & 2008 NRPN & Wesley//Pronghorn/Arlin \\
\hline HardingFhb1NIL09S-109 & HWW & HWWGRU & Sumai3/Harding*3 F4 \\
\hline CA9W06-788 & HWW & 2010 NRPN & Jerry/CDC Falcon \\
\hline OK Bullet ${ }^{\dagger}$ & HWW & Oklahoma State University & KS96WGRC39/Jagger \\
\hline ВC01139-1 & HWW & 2010 SRPN & W99-188\$-1/BC950285G-1-2 \\
\hline $\mathrm{CO} 050322$ & HWW & 2010 SRPN & CO980829/TAM 111 \\
\hline OK01420W & HWW & Oklahoma State University & KS93U206/Jagger RC \\
\hline NE06472 & HWW & 2008 RGON & CO95043 /KS89180B-2-1//NE98574 \\
\hline OK00514-05806 & HWW & 2008 SRPN & KS96WGRC39/Jagger \\
\hline
\end{tabular}

$\begin{array}{ll}50.6 \pm 33.8 & 65.6 \pm 9.4 \\ 51.5 \pm 22.2 & 55.9 \pm 18.0 \\ 51.5 \pm 21.3 & 32.2 \pm 16.8 \\ 51.6 \pm 16.7 & 71.3 \pm 14.8 \\ 52.0 \pm 17.1 & 38.8 \pm 14.7 \\ 52.0 \pm 14.6 & 41.3 \pm 15.9 \\ 52.5 \pm 19.2 & 58.8 \pm 6.8 \\ 52.8 \pm 24.8 & 45.4 \pm 16.1 \\ 53.1 \pm 20.4 & 44.4 \pm 10.4 \\ 53.1 \pm 16.8 & 31.3 \pm 4.6 \\ 53.5 \pm 6.9 & 56.3 \pm 13.1 \\ 54.8 \pm 30.9 & 65.0 \pm 13.7 \\ 55.0 \pm 26.6 & 61.8 \pm 16.0 \\ 55.4 \pm 32.4 & 52.6 \pm 27.9 \\ 55.6 \pm 13.6 & 44.5 \pm 8.9 \\ 55.8 \pm 10.2 & 45.0 \pm 0.0 \\ 56.5 \pm 9.0 & 80.0 \pm 12.2 \\ 57.5 \pm 8.5 & 67.5 \pm 20.6 \\ 57.6 \pm 14.3 & 55.0 \pm 20.6 \\ 57.7 \pm 21.5 & 68.0 \pm 19.3 \\ 57.9 \pm 10.1 & 67.5 \pm 17.1 \\ 58.5 \pm 22.5 & 68.8 \pm 7.5 \\ 59.0 \pm 27.9 & 58.4 \pm 31.7 \\ 59.1 \pm 18.5 & 36.9 \pm 15.6 \\ 59.2 \pm 16.7 & 50.0 \pm 5.6 \\ 59.3 \pm 21.7 & 76.8 \pm 17.5 \\ 59.5 \pm 16.0 & 76.9 \pm 9.4 \\ 60.1 \pm 19.9 & 66.9 \pm 16.4 \\ 60.4 \pm 29.5 & 77.5 \pm 15.3 \\ 60.6 \pm 11.1 & 79.3 \pm 18.4 \\ 61.4 \pm 31.5 & 53.2 \pm 21.7 \\ & \end{array}$




\begin{tabular}{|c|c|c|c|c|c|}
\hline 09-27-28 rec-989 & HWW & Kansas State University & CS-Leymus racemosus 7A translocation & $61.6 \pm 14.1$ & $47.5 \pm 2.5$ \\
\hline NE07688 & HWW & Tri-state FHB Nursery & OK93P656-RMH3299/NW97S278 & $61.7 \pm 12.3$ & $68.1 \pm 12.1$ \\
\hline Ike & HWW & PI 574488 & Dular/Eagle $/ / 2 *$ Cheney $/$ Larned $/ 3 /$ Colt & $61.9 \pm 16.2$ & $73.1 \pm 6.7$ \\
\hline MTS04120 & HWW & 2008 RGON & L'Govskaya 167/Rampart & $61.9 \pm 20.8$ & $53.7 \pm 25$ \\
\hline NE04424 & HWW & 2008 SRPN & KS92H363-2/Cougar sib & $62.0 \pm 26.4$ & $72.7 \pm 10.1$ \\
\hline SD03164-1 & HWW & 2008 NRPN & 89118RC1-X-9-3-3/TX96D2845//Expedition & $62.1 \pm 23.6$ & $42.7 \pm 22.1$ \\
\hline KS020304K 3 & HWW & 2008 RGON & Jagger/2137//KS940786-6-9 & $62.1 \pm 29.4$ & $73.8 \pm 15$. \\
\hline TX05V7259 & HWW & 2010 SRPN & T107//TX78V3620/Ctk78/3/TX87V1233/4/Arap//TX86V1540/T200 & $62.8 \pm 13.0$ & $70.6 \pm 10$ \\
\hline OK06848W & HWW & Oklahoma State University & OK94P461/Oro Blanco F6:11 & $63.8 \pm 34.2$ & $71.6 \pm 11.1$ \\
\hline JackPot & HWW & AgriPro Seeds Inc. & Unknown & $63.8 \pm 16.7$ & $67.5 \pm 5.6$ \\
\hline OK05212 & HWW & Oklahoma State University & OK95616-1/Hickok//Betty F4:10 & $64.0 \pm 15.2$ & $49.5 \pm 15$. \\
\hline OK03522 & HWW & 2008 SRPN & N566/OK94P597 & $64.0 \pm 18.0$ & $57.3 \pm 12$. \\
\hline NE06607 & HWW & 2010 NRPN & NE98466/Wesley & $64.1 \pm 16.5$ & $61.9 \pm 7.0$ \\
\hline $\mathrm{T}-136$ & HWW & Trio Seed Research. & Unknown & $64.2 \pm 23.0$ & $62.5 \pm 14$ \\
\hline NI07703 & HWW & 2010 SRPN & R-148 (G97343) /NI00436 & $64.3 \pm 20.6$ & $51.3 \pm 10$ \\
\hline Chisholm ${ }^{\dagger}$ & HWW & $\underline{\text { PI } 486219}$ & Sturdy sib/Nicoma & $64.3 \pm 20.2$ & $67.5 \pm 12$. \\
\hline HardingFhb1NIL09S-108 & HWW & HWWGRU & Sumai3/Harding*3 F4 & $64.7 \pm 11.0$ & $31.9 \pm 12.6$ \\
\hline NE06436 & HWW & 2008 RGON & Wesley/OK98699 & $64.8 \pm 32.5$ & $75.3 \pm 20.7$ \\
\hline TX06A001386 & HWW & 2010 SRPN & TX99A6030/Custer & $64.9 \pm 18.3$ & $75.0 \pm 16$. \\
\hline Scout $66^{\dagger}$ & HWW & CItr 13996 & Nebred//Hope/Turkey/3 Cheyenne/Ponca & $65.2 \pm 26.2$ & $75.3 \pm 14.2$ \\
\hline 2008-184 Overley (FHB3) & HWW & Kansas State University & Overley-Leymus racemosus 7A translocation & $65.3 \pm 9.7$ & $72.5 \pm 2.5$ \\
\hline MT0495 ${ }^{\dagger}$ & HWW & 2008 NRPN & MT9640/NB1133 & $65.4 \pm 29.5$ & $54.1 \pm 21.1$ \\
\hline SD06165 & HWW & 2008 NRPN & Wesley/SD97049 & $65.4 \pm 9.2$ & $69.0 \pm 5.0$ \\
\hline HV9W06-1046 & HWW & 2010 SRPN & M97-1171/G980039//G982238 & $65.4 \pm 10.8$ & $42.5 \pm 3.3$ \\
\hline KS980554-12- 9 & HWW & 2008 SRPN & $2180 * \mathrm{~K} / 2163 / / ? / 3 / \mathrm{W} 1062 \mathrm{~A} * \mathrm{HVA} 114 / \mathrm{W} 3416$ & $65.5 \pm 19.0$ & $64.4 \pm 16.6$ \\
\hline NH03614 (SETTLER) & HWW & Tri-state FHB Nursery & Wesley sib/Millennium sib/Above sib & $65.6 \pm 18.0$ & $38.8 \pm 10$ \\
\hline $\mathrm{CO} 03064$ & HWW & 2008 SRPN & CO970547/Prowers 99 & $65.9 \pm 32.1$ & $57.6 \pm 15.1$ \\
\hline $\mathrm{T}-140$ & HWW & Trio Seed Research & Unknown & $66.2 \pm 15.2$ & $66.3 \pm 6.1$ \\
\hline Infinity CL & HWW & AGSECO & Unknown & $66.4 \pm 5.7$ & $60.0 \pm 22.2$ \\
\hline $\mathrm{T} 151^{\dagger}$ & HWW & 2008 SRPN & T81/KS93U206 & $67.1 \pm 23.2$ & $44.6 \pm 10.8$ \\
\hline SD08138 & HWW & Tri-state FHB Nursery & SD92107-5/OK94P549-99-6704//Jagalene & $67.4 \pm 14.5$ & $61.9 \pm 7.5$ \\
\hline
\end{tabular}




\begin{tabular}{|c|c|c|c|c|c|}
\hline AP06T3621 & HWW & 2010 SRPN & X920232-5/Karl 92//X920750A-13-1 & $67.8 \pm 22.1$ & $78.8 \pm 7.9$ \\
\hline TX05A001334 & HWW & 2008 RGON & TX87V1233-3/U1254-4-6-6//K92/3/T200*2/TA2460*2//T202 & $68.0 \pm 31.2$ & $78.4 \pm 11.5$ \\
\hline OK03716W & HWW & Oklahoma State University & Oro Blanco/OK92403 F4:11 & $68.0 \pm 25.9$ & $70.6 \pm 25.7$ \\
\hline Fuller $^{\dagger}$ & HWW & Kansas State University & Unknown & $68.6 \pm 16.3$ & $47.2 \pm 19.5$ \\
\hline Hatcher & HWW & Colorado State University & Yuma/PI 372129//TAM 200/3/4* Yuma/4/KS91H184/Vista & $68.6 \pm 16.8$ & $77.5 \pm 8.3$ \\
\hline NE07531 & HWW & 2010 NRPN & HBK0630-4-5/NE98574 & $68.7 \pm 13.2$ & $62.5 \pm 18.5$ \\
\hline Armour & HWW & WestBred LLC. & Unknown & $69.2 \pm 21.7$ & $57.5 \pm 11.4$ \\
\hline Alliance & HWW & University of Nebraska & Arkan/Colt//Chisholm sib & $69.3 \pm 11.5$ & $79.4 \pm 5.1$ \\
\hline OK05903C & HWW & Oklahoma State University & TXGH12588-120*4/FS4//2174/3/Jagger F4:10 RC & $69.7 \pm 12.3$ & $47.3 \pm 15.6$ \\
\hline BZ9W05-2043 & HWW & 2010 NRPN & Rampart/Kestrel & $70.2 \pm 15.6$ & $62.5 \pm 6.6$ \\
\hline NE06549 & HWW & 2008 RGON & Hallam/Wesley & $70.3 \pm 22.8$ & $68.9 \pm 21.7$ \\
\hline MTS0721 & HWW & 2010 NRPN & DMS/Rampart//Pronghorn/3/2*Rampart & $70.6 \pm 7.0$ & $73.1 \pm 7.9$ \\
\hline NE02558 & HWW & 2008 NRPN & Jagger/Alliance & $70.6 \pm 22.5$ & $66.7 \pm 20.9$ \\
\hline HV9W04-1594R & HWW & 2010 NRPN & KS89180B-2-1-1/CMBW91M02959T//Jagger & $71.0 \pm 12.4$ & $47.5 \pm 7.5$ \\
\hline TAM 112 & HWW & Taxes A\&M University & TAM 200/TA2460//TXGH10440 & $71.2 \pm 15.4$ & $61.3 \pm 9.2$ \\
\hline KS010379M-2 & HWW & 2008 RGON & KS920709-B-5-2-2/TAM-400 & $71.8 \pm 12.5$ & $74.4 \pm 13.2$ \\
\hline OK03825-5403-6 & HWW & 2008 SRPN & Custer*3/94M81 & $71.8 \pm 10.6$ & $77.1 \pm 16.2$ \\
\hline T167 & HWW & 2010 SRPN & $\mathrm{T} 136 / \mathrm{T} 151$ & $71.8 \pm 13.5$ & $65.0 \pm 9.6$ \\
\hline $\mathrm{CO} 050303-2$ & HWW & 2010 SRPN & CO980829/TAM 111 & $72.5 \pm 15.0$ & $75.0 \pm 12.7$ \\
\hline NE05548 ${ }^{\dagger}$ & HWW & 2008 NRPN & Brigantina.2/Arapahoe//CO850267/Rawhide & $72.6 \pm 10.1$ & $56.0 \pm 21.4$ \\
\hline NI04427 & HWW & 2008 NRPN & KS98HW22//W95-615W/N94L189 & $72.8 \pm 13.7$ & $64.1 \pm 10.1$ \\
\hline T166 & HWW & 2010 SRPN & T81/KS93U206 & $73.9 \pm 19.3$ & $39.4 \pm 12.8$ \\
\hline NE04490 ${ }^{\dagger}$ & HWW & University of Nebraska & Unknown & $74.0 \pm 23.1$ & $68.3 \pm 16.5$ \\
\hline $\mathrm{OK} 02405^{\dagger}$ & HWW & 2008 RGON & Tonkawa/GK50 & $74.1 \pm 27.5$ & $42.0 \pm 18.6$ \\
\hline TX04A001246 & HWW & 2008 SRPN & TX95V4339/TX94VT938-6 & $74.4 \pm 20.7$ & $67.6 \pm 20.2$ \\
\hline T168 & HWW & 2010 SRPN & $\mathrm{T} 81 / \mathrm{T} 137$ & $74.8 \pm 17.0$ & $38.8 \pm 10.6$ \\
\hline HV9W05-881R & HWW & 2008 RGON & Mason/Ogallala-vr/Betty & $74.8 \pm 26.4$ & $84.9 \pm 9.4$ \\
\hline AP04T8211 ${ }^{\dagger}$ & HWW & 2008 SRPN & W98-232/KS96WGRC38 & $75.0 \pm 18.9$ & $55.5 \pm 18.6$ \\
\hline TAM- $107^{\dagger}$ & HWW & 2008 SRPN & TAM 105*4/Amigo & $75.4 \pm 23.3$ & $73.5 \pm 21.7$ \\
\hline 2008-191 Jagger (FHB3) & HWW & Kansas State University & Jagger-Leymus racemosus 7 A translocation & $75.5 \pm 5.6$ & $63.8 \pm 6.3$ \\
\hline KS010957K 4 & HWW & 2008 RGON & 2145/Karl 92//KS940786-6-11 & $75.6 \pm 27.3$ & $76.0 \pm 21.0$ \\
\hline
\end{tabular}




\begin{tabular}{|c|c|c|c|}
\hline HV9W05-1125R & HWW & 2010 NRPN & 00KSULR-73/G980039 \\
\hline MT0552 & HWW & 2008 NRPN & N95L159/CDC Clair \\
\hline N98L20040-44 & HWW & 2008 NRPN & CS/PI467024//CS/3/SXLD/4/TAM202/5/SXLD \\
\hline АР06Т3832 & HWW & 2008 SRPN & HBK0935-29-15/KS90W077-2-2/VBF0589-1 \\
\hline TX01V5134RC-3 & HWW & 2008 SRPN & TAM-200/Jagger \\
\hline $00 \times 0100-51$ & HWW & 2010 NRPN & W95-301/W98-151 \\
\hline NE07521 & HWW & 2010 NRPN & (Yuma/T-57//Lamar/3/4*Yuma/4/New516)/NI00436 \\
\hline HV9W03-539R & HWW & 2008 SRPN & KS94U275/1878//Jagger \\
\hline TX05V7269 & HWW & 2010 SRPN & HBG0358/4/T107//TX78V3620/Ctk78/3/TX87V1233 \\
\hline TX04M410164 & HWW & 2008 SRPN & MIT/TX93V5722//W95-301 \\
\hline OK05204 & HWW & 2010 SRPN & SWM866442/OK95548 F4:12 \\
\hline SD06173 & HWW & 2008 NRPN & Bulk02R2B \\
\hline CA9W07-817 & HWW & 2010 NRPN & CDC Falcon/Jerry \\
\hline $\mathrm{CO} 050270$ & HWW & 2010 SRPN & Hatcher/NW97S295 \\
\hline TX05V5614 & HWW & 2008 RGON & TX96V2427/TX98U8083 \\
\hline PHS2008F206bab & HWW & Kansas State University & Rioblanco/NW97S187 \\
\hline Karl 92 & HWW & PI 564245 & Plainsman V/3/Kaw/Atlas 50//Parker *5/Agent \\
\hline OK05830 & HWW & Oklahoma State University & OK93617/Jagger F6:12 \\
\hline OK06345 & HWW & Oklahoma State University & Fawwon 06/2174//OK95548-26C F4:9 \\
\hline $\mathrm{CO} 050337-2$ & HWW & 2010 SRPN & CO980829/TAM 111 \\
\hline NE05430 & HWW & 2008 SRPN & IN92823A1-1-4-5/NE92458 \\
\hline TX05A001822 & HWW & 2010 SRPN & 2145/X940786-6-7 \\
\hline NE05549 & HWW & 2008 NRPN & NE90614/NE87612//NE87612//Wesley \\
\hline NE05496 & HWW & 2008 SRPN & KS87H325/Rioblanco//Hallam \\
\hline Duster $^{\dagger}$ & HWW & Oklahoma State University & W0405/NE78488//W7469C/TX81V6187 \\
\hline TX06A001263 & HWW & 2010 SRPN & TX97V3006/TX98V6239 \\
\hline NE01481 & HWW & Tri-state FHB Nursery & OK83201/Redland//ke \\
\hline KS030024-K-3 & HWW & Tri-state FHB Nursery & KS89180B-2-1-2/3/Karl 92*2/Ravi-36 \\
\hline TAM $110^{\dagger}$ & HWW & Taxes A\&M University & TAM105*4/Amigo*5/Largo \\
\hline SD07204 & HWW & 2008 RGON & Harding//SD98243/Alliance \\
\hline KS011327M 2 & HWW & 2010 SRPN & KS940748-2-4/TX97V4311//Overley \\
\hline
\end{tabular}

\begin{tabular}{ll}
$75.9 \pm 14.8$ & $70.0 \pm 5.4$ \\
$76.0 \pm 18.6$ & $75.5 \pm 12.5$ \\
$76.7 \pm 21.0$ & $90.5 \pm 12.4$ \\
$76.8 \pm 27.6$ & $60.2 \pm 19.1$ \\
$77.0 \pm 17.3$ & $62.6 \pm 18.0$ \\
$77.0 \pm 17.4$ & $63.8 \pm 9.5$ \\
$77.2 \pm 13.0$ & $86.9 \pm 8.5$ \\
$77.2 \pm 17.1$ & $63.7 \pm 21.2$ \\
$77.3 \pm 12.5$ & $58.8 \pm 8.8$ \\
$77.8 \pm 28.8$ & $75.7 \pm 27.6$ \\
$77.8 \pm 12.3$ & $68.8 \pm 13.6$ \\
$78.4 \pm 14.5$ & $48.3 \pm 16.0$ \\
$78.8 \pm 12.4$ & $30.0 \pm 5.7$ \\
$78.8 \pm 15.2$ & $56.9 \pm 14.6$ \\
$78.9 \pm 15.1$ & $75.0 \pm 14.5$ \\
$79.1 \pm 16.3$ & $86.3 \pm 3.7$ \\
$79.2 \pm 18.5$ & $32.5 \pm 5.4$ \\
$79.6 \pm 18.9$ & $60.3 \pm 17.8$ \\
$79.7 \pm 14.8$ & $79.7 \pm 14.8$ \\
$79.8 \pm 12.9$ & $71.9 \pm 10.7$ \\
$80.0 \pm 19.8$ & $60.2 \pm 18.5$ \\
$80.6 \pm 20.7$ & $86.3 \pm 8.9$ \\
$80.9 \pm 9.1$ & $53.8 \pm 29.9$ \\
$80.9 \pm 16.1$ & $86.5 \pm 9.8$ \\
$81.3 \pm 18.7$ & $85.9 \pm 8.3$ \\
$81.9 \pm 12.9$ & $81.3 \pm 8.7$ \\
$82.0 \pm 9.6$ & $87.5 \pm 2.2$ \\
$82.2 \pm 17.9$ & $30.0 \pm 6.5$ \\
$82.2 \pm 15.9$ & $67.4 \pm 29.6$ \\
$83.0 \pm 10.3$ & $61.3 \pm 26.6$ \\
$83.1 \pm 12.0$ & $96.9 \pm 2.8$ \\
& \\
\hline &
\end{tabular}




\begin{tabular}{|c|c|c|c|c|c|}
\hline Santa Fe & HWW & AGSECO & Unknown & $83.1 \pm 17.0$ & $38.1 \pm 5.3$ \\
\hline Jagger & HWW & PI 593688 & KS82W418/Stephens & $83.2 \pm 14.5$ & $55.0 \pm 16.7$ \\
\hline Keota & HWW & Westbred LLC. & Unknown & $83.5 \pm 9.1$ & $81.9 \pm 15.8$ \\
\hline OK06518 & HWW & Oklahoma State University & Palma/Hickok//2174 F4:9 & $83.6 \pm 17.9$ & $48.3 \pm 24.1$ \\
\hline Jagalene & HWW & AgriPro Seeds Inc. & Jagger/Abilene & $83.7 \pm 20.3$ & $81.3 \pm 5.3$ \\
\hline OK04525 & HWW & Oklahoma State University & FFR525W/Hickok//Coronado F4:11 & $83.9 \pm 15.0$ & $59.5 \pm 8.5$ \\
\hline OK04505 & HWW & 2008 SRPN & OK91724/2*Jagger & $84.3 \pm 12.2$ & $69.2 \pm 12.7$ \\
\hline KS021006-NT-9 & HWW & Tri-state FHB Nursery & KS920709-B-5-1-1/Cutter//Jagger & $84.5 \pm 11.0$ & $88.1 \pm 3.6$ \\
\hline TXHT006F8-CS06/472-STA34 & HWW & 2008 RGON & Lockett/Halberd & $84.7 \pm 14.4$ & $76.5 \pm 18.3$ \\
\hline KS010514-9TM-10 & HWW & 2008 RGON & CM98-42/3/HBF0290/X84W063-9-39-2//ARH/4/KS940786-6-4 & $85.0 \pm 25.8$ & $85.4 \pm 11.7$ \\
\hline ТХHТ023F7-CS06/607-STA07/40 & HWW & 2008 RGON & TX99U8544/Ogallala & $85.7 \pm 20.4$ & $76.1 \pm 25.8$ \\
\hline Protection CL & HWW & AGSECO & Unknown & $85.8 \pm 17.0$ & $86.3 \pm 5.8$ \\
\hline HV9W96-1271R-1 & HWW & 2008 SRPN & HV9W00-1551WP/KS94U326 & $85.9 \pm 13.2$ & $63.6 \pm 17.0$ \\
\hline OK04507 & HWW & 2008 RGON & OK95593/Jagger//2174 & $86.2 \pm 13.6$ & $85.6 \pm 15.4$ \\
\hline OK05526 & HWW & 2010 SRPN & KS94U275/OK94P549 F4:12 & $86.2 \pm 11.8$ & $41.9 \pm 13.6$ \\
\hline SD08174 & HWW & Tri-state FHB Nursery & Ransom/Cutter/NW99L7068 & $86.2 \pm 13.2$ & $92.5 \pm 4.8$ \\
\hline KS030101-M-2 & HWW & Tri-state FHB Nursery & KS00F5-20-3/KS00F5-14-4 & $86.6 \pm 19.3$ & $56.3 \pm 7.3$ \\
\hline TX03A0148 & HWW & 2008 SRPN & TX89A7137/Tipacna & $86.7 \pm 21.2$ & $69.5 \pm 20.4$ \\
\hline $\mathrm{T} 158$ & HWW & 2008 SRPN & KS93U206/2*T81 & $86.9 \pm 16.7$ & $84.6 \pm 9.8$ \\
\hline TX06A001281 & HWW & 2010 SRPN & TX98VR8422/U3704A-7-7 & $87.0 \pm 8.9$ & $70.6 \pm 11.5$ \\
\hline NE08452 & HWW & Tri-state FHB Nursery & (Brigantina/2*Arapahoe)/OK96717-99-6756 & $87.3 \pm 12.0$ & $76.3 \pm 16.3$ \\
\hline TX04V075080 & HWW & 2008 SRPN & Jagger/TX93V5722//TX95D8905 & $87.3 \pm 9.0$ & $84.5 \pm 7.1$ \\
\hline TAM-304 & HWW & Taxes A\&M University & (WO541A/W2440//W2407/Arkan)/(TX85V1326/TX86D1312) & $87.5 \pm 9.8$ & $72.5 \pm 8.3$ \\
\hline HV9W06-509 & HWW & 2010 SRPN & G982231/G982159//KS920709W & $87.6 \pm 16.3$ & $89.4 \pm 4.3$ \\
\hline Smoky Hill & HWW & Westbred LLC. & Unknown & $87.7 \pm 10.6$ & $71.3 \pm 18.4$ \\
\hline HV9W03-696R-1 & HWW & 2008 SRPN & N94L027/Tbolt//KS89180B & $87.7 \pm 15.7$ & $74.2 \pm 21.3$ \\
\hline TX05A001188 & HWW & 2010 SRPN & T107//TX98V3620/Ctk78/3/TX87V1233/4/N87V106//TX86V1540/T200 & $87.8 \pm 13.2$ & $90.0 \pm 6.1$ \\
\hline KS08P1-108 & HWW & Tri-state FHB Nursery & KS89180B-2-1-2/3/Karl 92/Ravi-36 & $88.0 \pm 7.7$ & $50.0 \pm 5.4$ \\
\hline SD07056 & HWW & Tri-state FHB Nursery & Falcon/SD97060//Jagalene & $88.8 \pm 18.0$ & $87.5 \pm 11.5$ \\
\hline PHS2008F212bbb & HWW & Kansas State University & Rioblanco/NW97S186 & $89.1 \pm 9.8$ & $87.5 \pm 2.5$ \\
\hline KS030024-K-4 & HWW & Tri-state FHB Nursery & KS89180B-2-1-2/3/Karl 92*2/Ravi-36 & $89.3 \pm 13.3$ & $38.8 \pm 6.6$ \\
\hline
\end{tabular}




\begin{tabular}{|c|c|c|c|c|c|}
\hline OK05511 & HWW & 2008 RGON & TAM $110 / 2174$ & $89.9 \pm 8.0$ & $65.6 \pm 26.3$ \\
\hline KS030124-K-4 & HWW & Tri-state FHB Nursery & Fuller/Jagalene & $90.0 \pm 9.4$ & $75.0 \pm 9.6$ \\
\hline Overley $^{\dagger}$ & HWW & Kansas State University & U1275-1-4-2-2/Heyne ‘S'/Jagger & $90.3 \pm 18.5$ & $79.6 \pm 22.2$ \\
\hline NW03666 & HWW & 2008 NRPN & N94S097KS/NE93459 & $90.5 \pm 11.5$ & $68.0 \pm 15.2$ \\
\hline NX04Y2107 & HWW & 2008 NRPN & NW98S081/99Y1442 & $90.6 \pm 7.5$ & $82.8 \pm 16.1$ \\
\hline OK05122 & HWW & Okalahoma State University & KS94U337/NE93427 F4:10 & $90.7 \pm 4.0$ & $75.6 \pm 20.3$ \\
\hline KS08IFAFS1 & HWW & Tri-state FHB Nursery & Karl 92*5/McVey & $90.7 \pm 4.0$ & $25.0 \pm 7.2$ \\
\hline $\mathrm{T} 81$ & HWW & Trio Seed Research & Unknown & $91.4 \pm 10.9$ & $66.3 \pm 7.9$ \\
\hline OK03305 & HWW & 2008 SRPN & N40/OK94P455 & $91.5 \pm 8.1$ & $90.1 \pm 12.2$ \\
\hline NE05426 & HWW & 2008 SRPN & W95-091 (=KS85-663-8-9//WI81-133/Thunderbird)/Akron & $91.7 \pm 6.7$ & $93.9 \pm 4.8$ \\
\hline KS06O3A 50-3 & HWW & 2010 SRPN & Overley*3/Amadina & $91.9 \pm 10.5$ & $78.8 \pm 8.8$ \\
\hline TX06A001239 & HWW & 2008 RGON & Ogallala/KS94U275 & $92.1 \pm 12.8$ & $81.0 \pm 12.6$ \\
\hline TAM111 & HWW & Taxes A\&M University & TAM 107//TX78V3630/Centurk 78/3/TX87V1233 & $92.2 \pm 11.0$ & $72.5 \pm 6.6$ \\
\hline HV9W06-262 & HWW & 2010 SRPN & TX98U8134/3/Karl 92*2/Ravi-36 & $92.6 \pm 10.7$ & $70.0 \pm 7.4$ \\
\hline KS07F5BULK01-K-7 & HWW & Tri-state FHB Nursery & Bulk Selection & $92.8 \pm 9.3$ & $58.8 \pm 10.4$ \\
\hline OK07209 & HWW & 2010 SRPN & OK93P656-(RMH 3299)/OK99621 F4:10 & $93.1 \pm 6.3$ & $87.5 \pm 9.4$ \\
\hline TX06A001084 & HWW & 2008 RGON & KS90WGRC10//U1275-1-11-8/TA2455/3/KS93U69/4/Ogallala/TX89V4133 & $93.1 \pm 11.0$ & $83.0 \pm 14.1$ \\
\hline TX06A001431 & HWW & 2008 RGON & T107//TX98V3620/Ctk78/3/TX87V1233/4/N87V106//TX86V1540/T200 & $93.3 \pm 14.9$ & $93.3 \pm 7.5$ \\
\hline NX03Y2489 & HWW & 2008 NRPN & BaiHuo/Kanto107//Ike/3/KS91H184/3*RBL//N87V106 & $93.7 \pm 10.7$ & $92.9 \pm 9.9$ \\
\hline Deliver & HWW & Oklahoma State University & OK91724/Karl & $93.9 \pm 6.2$ & $77.2 \pm 13.4$ \\
\hline TX04M410211 & HWW & 2008 SRPN & Mason/Jagger//Ogallala & $94.6 \pm 4.4$ & $96.0 \pm 4.5$ \\
\hline ВC01138-5 & HWW & 2010 SRPN & W99-188\$/BC950814-1-1 & $96.1 \pm 8.6$ & $57.5 \pm 7.9$ \\
\hline Guymon & HWW & Oklahoma State University & Intrada/Platte & $96.3 \pm 5.1$ & $94.5 \pm 6.7$ \\
\hline SD06W117 & HWW & 2008 NRPN & Alice/SD00W024 & $96.5 \pm 5.3$ & $85.3 \pm 13.5$ \\
\hline TX03A0563 & HWW & 2008 SRPN & X96V107/Ogallala & $96.8 \pm 3.2$ & $88.5 \pm 10.3$ \\
\hline TX06A001132 & HWW & 2010 SRPN & HBG0358/4/T107//TX78V3620/Ctk78/3/TX87V1233 & $97.0 \pm 4.3$ & $93.8 \pm 8.8$ \\
\hline KS06O3A 58-2 & HWW & 2010 SRPN & Overley*3/Amadina & $97.0 \pm 4.2$ & $72.5 \pm 11.2$ \\
\hline Postrock & HWW & AgriPro Seeds Inc. & Unknown & $97.1 \pm 4.9$ & $74.4 \pm 7.8$ \\
\hline 09-26-6 rec-679 & HWW & Kansas State University & CS-Leymus racemosus 7A translocation & $97.9 \pm 3.6$ & $85.0 \pm 0.0$ \\
\hline TX02A0252 & HWW & 2008 SRPN & TX90V6313//TX94V3724/TX86V1405 & $98.5 \pm 3.4$ & $91.9 \pm 6.0$ \\
\hline KS020648-M-6 & HWW & Tri-state FHB Nursery & Overley/Karl 92//Jagalene & $99.5 \pm 0.7$ & $85.6 \pm 4.2$ \\
\hline
\end{tabular}




\begin{tabular}{|c|c|c|c|c|c|}
\hline BC01131-24 & HWW & 2010 SRPN & W99-429-1/W98-422 & $99.6 \pm 0.9$ & $76.3 \pm 5.6$ \\
\hline SD08145 & HWW & Tri-state FHB Nursery & SD92107-5/OK94P549-99-6704//Jagalene & $99.8 \pm 0.5$ & $84.4 \pm 10.0$ \\
\hline KS030049-NT-7 & HWW & Tri-state FHB Nursery & TX97V4311/3/Karl 92*2/Ravi-36 & $100.0 \pm 0.0$ & $70.6 \pm 9.7$ \\
\hline OK06210 & HWW & Oklahoma State University & $\begin{array}{l}\text { KS90175-1-2/CMSW89Y271//K92/3/ABI86*3414/X86035*-BB-34//HBC 302E } \\
\text { RC F4:9 RC }\end{array}$ & $100.0 \pm 0.0$ & $94.2 \pm 8.4$ \\
\hline Heyne & HWW & PI 612577 & KS82W422/SWM754308/KS831182/KS82W422 & $18.6 \pm 15.4$ & $35.6 \pm 7.4$ \\
\hline TregoFhb1NIL09S-98 & HWW & HWWGRU & ND2710/Trego/Trego F4 & $21.0 \pm 5.5$ & $25.6 \pm 10.3$ \\
\hline TregoFhb1NIL09S-99 & HWW & HWWGRU & ND2710/Trego/Trego F4 & $21.6 \pm 9.4$ & $18.1 \pm 3.4$ \\
\hline $\mathrm{CO} 04 \mathrm{~W} 210$ & HWW & 2008 RGON & NW97S343/Akron & $28.0 \pm 12.0$ & $38.3 \pm 13.7$ \\
\hline Aspen & HWW & WestBred LLC. & Unknown & $30.2 \pm 11.6$ & $28.1 \pm 6.8$ \\
\hline KS07HW25 & HWW & 2008 RGON & KS025580(Trego/CO960293)/KSO1HW152-6(Tgo/Bty sib) & $38.3 \pm 16.2$ & $59.6 \pm 24.4$ \\
\hline SD07184 & HWW & Tri-state FHB Nursery & Expedition/SD97W650//KS00H10-32-1-1 & $39.8 \pm 8.5$ & $55.6 \pm 9.0$ \\
\hline NW05M6011-6-1 & HWW & 2008 RGON & Nuplains/Arrowsmith & $40.0 \pm 22.9$ & $45.5 \pm 5.5$ \\
\hline TregoFhb1NIL09S-100 & HWW & HWWGRU & ND2710/Trego/Trego F4 & $45.6 \pm 10.8$ & $18.8 \pm 5.9$ \\
\hline MTS0532 & HWW & 2010 NRPN & L'Govskaya 167/Rampart/MT9409 & $46.7 \pm 18.1$ & $51.9 \pm 7.6$ \\
\hline $\mathrm{SD} 05 \mathrm{~W} 030^{\dagger}$ & HWW & 2008 NRPN & SD98W302/NW97S186 & $48.8 \pm 34.2$ & $81.4 \pm 11.7$ \\
\hline SD05W148-1 & HWW & 2008 RGON & SD98153/SD98W117 & $50.6 \pm 31.5$ & $45.3 \pm 21.5$ \\
\hline $\mathrm{CO} 04393$ & HWW & 2010 SRPN & Stanton/CO950043 & $51.2 \pm 25.3$ & $74.4 \pm 14.3$ \\
\hline Lakin & HWW & PI 617032 & KS89H130/Arlin & $52.3 \pm 8.5$ & $41.3 \pm 8.6$ \\
\hline SD07126 & HWW & Tri-state FHB Nursery & SD92107-2/SD99W042 & $54.4 \pm 11.2$ & $43.8 \pm 6.6$ \\
\hline KS05HW121-2 & HWW & 2008 SRPN & KS99-5-16//Stanton/KS98HW423 & $58.0 \pm 17.7$ & $73.1 \pm 18.5$ \\
\hline $\mathrm{CO} 03 \mathrm{~W} 139^{\dagger}$ & HWW & 2008 SRPN & CO980862/Lakin & $59.9 \pm 25.8$ & $27.3 \pm 13.9$ \\
\hline KS05HW15-2 & HWW & 2008 SRPN & KS98HW452/CO960293//KS920709B-5-2 & $60.7 \pm 24.1$ & $67.3 \pm 26.2$ \\
\hline CO03W054 & HWW & 2008 SRPN & KS96HW94//Trego/CO960293 & $63.6 \pm 34.8$ & $64.5 \pm 19.1$ \\
\hline NX05M4180-6 & HWW & 2010 NRPN & 92201D5-2-29 X 99 waxy bulk & $64.4 \pm 25.8$ & $75.6 \pm 10.4$ \\
\hline $\mathrm{T} 150-1$ & HWW & 2010 SRPN & T81/T201 & $65.2 \pm 15.4$ & $71.3 \pm 13.6$ \\
\hline CO03W043 & HWW & 2008 SRPN & KS96HW94/CO980352 & $65.7 \pm 25.9$ & $71.4 \pm 19.0$ \\
\hline NW07534 & HWW & Tri-state FHB Nursery & KS920709-B-5-2/NW98S061 & $68.1 \pm 12.3$ & $78.1 \pm 7.4$ \\
\hline 2137 & HWW & Kansas State University & W2440/W9488A//2163 & $69.1 \pm 13.2$ & $74.4 \pm 15.5$ \\
\hline $\mathrm{CO} 02 \mathrm{~W} 237$ & HWW & 2008 SRPN & 98HW519/96HW94 & $70.3 \pm 22.3$ & $83.7 \pm 18.3$ \\
\hline NW05M6015-25-4 & HWW & 2008 RGON & NW97S186/Rioblanco & $72.1 \pm 25.6$ & $34.1 \pm 28.5$ \\
\hline
\end{tabular}




\begin{tabular}{|c|c|c|c|c|c|}
\hline KS07HW52-5 & HWW & 2010 SRPN & KS025580(Trego/CO960293)/KS02HW25(Tgo/Jgr 8W) & $72.8 \pm 11.7$ & $62.5 \pm 19.5$ \\
\hline NI08708 & HWW & 2010 SRPN & CO980829 (=Yuma/T-57//CO850034/3/4*Yuma/4/NEWS1)/Wesley & $73.8 \pm 16.6$ & $50.0 \pm 5.6$ \\
\hline KS05HW136-3 & HWW & 2008 SRPN & KS98HW518(93HW91/93HW255)//KS98H245(Ike/TA2460//*3T200)/Trego & $77.0 \pm 15.5$ & $77.0 \pm 11.1$ \\
\hline NW04Y2188 & HWW & 2008 NRPN & MO8/Redland//KS91H184/3*Rioblanco & $78.4 \pm 20.0$ & $67.1 \pm 26.2$ \\
\hline SD07W041 & HWW & 2008 RGON & Falcon/SD99W042//Trego & $79.8 \pm 14.4$ & $79.6 \pm 16.8$ \\
\hline Danby & HWW & Kansas State University & Trego/KS84063-9-39-3-8w & $81.6 \pm 24.6$ & $81.3 \pm 6.0$ \\
\hline Rioblanco & HWW & PI 531244 & OK11252A/W76-1226 & $83.3 \pm 23.9$ & $83.8 \pm 9.3$ \\
\hline KS07HW81 & HWW & 2008 RGON & KS02HW25/KS00HW114-1-1 & $84.3 \pm 13.7$ & $79.4 \pm 16.0$ \\
\hline Antelope & HWW & PI 633910 & Pronghorn/Arlin & $85.8 \pm 9.3$ & $66.7 \pm 21.8$ \\
\hline KS07HW117 & HWW & 2008 RGON & KS00HW151-4//KS98HW151-6/00HW114-1 & $86.3 \pm 20.3$ & $74.8 \pm 17.1$ \\
\hline Trego $^{\dagger}$ & HWW & 2008 SRPN & KS87H325/Rioblanco & $87.7 \pm 15.6$ & $80.9 \pm 15.6$ \\
\hline KS010990M 8 & HWW & 2010 SRPN & Trego/Ventnor/KS940786-6-4 & $91.6 \pm 7.6$ & $94.4 \pm 6.8$ \\
\hline KS08HW176-4 & HWW & 2010 SRPN & Trego/Jagger 8W & $91.6 \pm 13.2$ & $92.5 \pm 2.2$ \\
\hline CO03W239 & HWW & 2008 SRPN & KS01-5539/CO99W165 & $98.8 \pm 2.5$ & $99.0 \pm 2.3$ \\
\hline INW0411 & SWW & UESRWWN & 96204A1-12//Goldfield/92823A1-11 & $5.9 \pm 2.6$ & $27.8 \pm 32.8$ \\
\hline Freedom & SWW & PI 531244 & OK11252A/W76-1226 & $7.6 \pm 3.0$ & $32.4 \pm 25.2$ \\
\hline MO040152 & SWW & UESRWWN & MO 12278/Pio2571 & $9.5 \pm 1.7$ & $25.2 \pm 14.2$ \\
\hline Roane & SWW & UESRWWN & VA71-54-147/C68-15//IN65309C1-18-2-3-2 & $10.7 \pm 4.8$ & $19.3 \pm 7.4$ \\
\hline Bess & SWW & PI 642794 & MO11769/Madison & $17.2 \pm 14.4$ & $36.8 \pm 28.2$ \\
\hline P03207A1-7 & SWW & UESRWWN & INW0304*2/RSI5//981281/3/INW0315/99794 & $18.8 \pm 12.3$ & $50.2 \pm 26.7$ \\
\hline KY96C-0769-7-3 & SWW & UESRWWN & 2552/Roane & $19.9 \pm 11.1$ & $24.7 \pm 7.9$ \\
\hline Atlas 66 & SWW & CItr 12561 & Frondoso//Redhart 3/Noll 28(sister selection of Atlas 50) & $21.4 \pm 13.4$ & $43.9 \pm 13.9$ \\
\hline IL00-8530 & SWW & UESRWWN & IL89-1687/IL90-6364/IL93-2489 & $23.6 \pm 15.6$ & $36.4 \pm 19.5$ \\
\hline MD01W233-06-1 & SWW & USSRWWN & McCormick/Choptank & $24.6 \pm 17.9$ & $27.2 \pm 10.7$ \\
\hline USG 3555 & SWW & USSRWWN & VA94-52-60/Pio2643//USG3209 & $25.2 \pm 13.7$ & $23.3 \pm 12.4$ \\
\hline M04*5109 & SWW & UESRWWN & VA94-54-479/Pio2628 & $26.6 \pm 23.6$ & $28.9 \pm 8.2$ \\
\hline ClarkFhb1NIL-75 & SWW & HWWGRU & Ning7840/Clark*7 & $26.7 \pm 7.1$ & $13.8 \pm 2.5$ \\
\hline ClarkFhb1NIL09F-23 & SWW & HWWGRU & Ning7840/Clark*7 & $27.1 \pm 3.3$ & $12.5 \pm 2.7$ \\
\hline G69202 & SWW & UESRWWN & VA91-54-219/OH413 & $27.6 \pm 30.4$ & $37.6 \pm 26.4$ \\
\hline Ernie & SWW & PI 584525 & Pike/MO9965 & $27.8 \pm 14.0$ & $26.7 \pm 14.3$ \\
\hline ClarkFhb1NIL09F-45 & SWW & HWWGRU & Ning7840/Clark*7 & $30.2 \pm 21.0$ & $18.1 \pm 5.1$ \\
\hline
\end{tabular}




$\begin{array}{lll}\text { OH02-12678 } & \text { SWW } & \text { UESRWWN } \\ \text { M03-3616-C } & \text { SWW } & \text { USSRWWN } \\ \text { OH02-7217 } & \text { SWW } & \text { UESRWWN } \\ \text { P02444A1-23-9 } & \text { SWW } & \text { UESRWWN } \\ \text { MD99W483-06-9 } & \text { SWW } & \text { UESRWWN } \\ \text { P03112A1-7-14 } & \text { SWW } & \text { USSRWWN } \\ \text { KY97C-0519-04-07 } & \text { SWW } & \text { UESRWWN } \\ \text { P04287A1-10 } & \text { SWW } & \text { USSRWWN } \\ \text { W06-202B } & \text { SWW } & \text { UESRWWN } \\ \text { AR96077-7-2 } & \text { SWW } & \text { USSRWWN } \\ \text { G61505 } & \text { SWW } & \text { USSRWWN } \\ \text { G41732 } & \text { SWW } & \text { USSRWWN } \\ \text { M04-4715 } & \text { SWW } & \text { USSRWWN } \\ \text { B030543 } & \text { SWW } & \text { USSRWWN } \\ \text { MO011126 } & \text { SWW } & \text { UESRWWN } \\ \text { Mocha exp. } & \text { SWW } & \text { UESRWWN } \\ \text { AR97124-4-3 } & \text { SWW } & \text { USSRWWN } \\ \text { LA01*425 } & \text { SWW } & \text { UESRWWN } \\ \text { NC04-15533 } & \text { SWW } & \text { USSRWWN } \\ \text { D04*5513 } & \text { SWW } & \text { UESRWWN } \\ \text { AR97044-10-2 } & \text { SWW } & \text { UESRWWN } \\ \text { ClarkFhb1NIL09F-4 } & \text { SWW } & \text { HWWGRU } \\ \text { VA04W-259 } & \text { SWW } & \text { USSRWWN } \\ \text { IL02-18228 } & \text { SWW } & \text { UESRWWN } \\ \text { G59160 } & \text { SWW } & \text { USSRWWN } \\ \text { Branson } & \text { SWW } & \text { UESRWWN } \\ \text { M04-4802 } & \text { SWW } & \text { UESRWWN } \\ \text { India exp. } & \text { SWW } & \text { UESRWWN } \\ \text { Pioneer Brand 26R61 } & \text { SWW } & \text { USSRWWN } \\ \text { IL02-19463 } & \text { SWW } & \text { UESRWWN } \\ \text { M04-4566 } & \text { SWW } & \text { UESRWWN } \\ & & \\ & & \end{array}$

Foster/Hopewel1//OH581/OH569

Hopewell/Patton

92118B4-2/OH561

981129/99793//INW0301/92145

VA97W358/Renwood 3260

INW0411//INW0315/99794

SS555W/2540//2552

INW0315*2/4/INW0304//9346/CS 5Am/3/91202//INW0301/INW0315

Ashland/Hopewell//OH546/L930605

Jackson/Pio2643

ABI89-4584A/T814

T814/L900819

Mason/Ernie

VA93-54-429/LA85422

MO94-103/Pio2552

$\mathrm{OH} 489 / \mathrm{OH} 490$

P88288C1-6-1-2/Terra SR204

P2571/Y91-6B

NC94-6275/P86958//VA96-54-234

DK1551W/D94-50228

Elkhart/AR494B-2-2

Ning7840/Clark*7

VA97W-533 /NC95-11612

Pio25R26/IL9634-24437(IL90-4813/L85-3132/Ning7840)//IL95-4162

T812/VA91-54-219

Pio2737W/891-4584A

FFR518//Elkhart/MV-18

KY85C-35-4/Karl/Madison

Omega78/S76/4/Arthur71/3/Stadler//Redcoat/Wisc1/5/Coker747/6/2555 sib

Patton/Cardinal//IL96-2550

Bradley/Roane

\begin{tabular}{ll}
$30.5 \pm 14.8$ & $35.0 \pm 14.9$ \\
$31.5 \pm 17.1$ & $22.6 \pm 9.0$ \\
$32.8 \pm 7.7$ & $35.5 \pm 10.7$ \\
$34.9 \pm 30.4$ & $21.2 \pm 14.7$ \\
$35.2 \pm 18.8$ & $43.5 \pm 16.9$ \\
$35.6 \pm 30.4$ & $47.9 \pm 24.8$ \\
$35.9 \pm 27.2$ & $32.9 \pm 9.4$ \\
$36.7 \pm 15.8$ & $35.2 \pm 4.6$ \\
$37.4 \pm 20.3$ & $52.1 \pm 13.9$ \\
$37.6 \pm 18.6$ & $51.7 \pm 24.0$ \\
$39.9 \pm 33.6$ & $24.1 \pm 8.8$ \\
$42.2 \pm 27.1$ & $23.0 \pm 11.7$ \\
$42.4 \pm 29.2$ & $32.3 \pm 12.4$ \\
$42.8 \pm 29.5$ & $68.6 \pm 67.5$ \\
$43.5 \pm 15.5$ & $28.0 \pm 13.5$ \\
$45.1 \pm 21.8$ & $55.9 \pm 20.5$ \\
$48.8 \pm 13.0$ & $66.9 \pm 8.5$ \\
$52.4 \pm 36.9$ & $50.6 \pm 14.3$ \\
$52.4 \pm 22.2$ & $45.3 \pm 9.8$ \\
$53.2 \pm 28.1$ & $58.2 \pm 19.4$ \\
$53.8 \pm 25.9$ & $62.7 \pm 13.8$ \\
$53.9 \pm 14.8$ & $20.6 \pm 9.2$ \\
$54.3 \pm 28.7$ & $74.4 \pm 14.0$ \\
$54.7 \pm 27.5$ & $18.6 \pm 10.2$ \\
$56.3 \pm 12.7$ & $31.7 \pm 12.6$ \\
$57.3 \pm 22.7$ & $49.3 \pm 22.6$ \\
$57.5 \pm 33.5$ & $56.1 \pm 17.3$ \\
$60.3 \pm 28.2$ & $38.7 \pm 33.6$ \\
$63.1 \pm 40.5$ & $56.4 \pm 34.8$ \\
$66.6 \pm 28.6$ & $57.9 \pm 25.6$ \\
$66.9 \pm 16.0$ & $67.7 \pm 22.2$ \\
& \\
\hline &
\end{tabular}




\begin{tabular}{|c|c|c|c|c|c|}
\hline W98007V1 & SWW & USSRWWN & F2IN82104B1-3-2(H14H15) & $67.2 \pm 28.2$ & $59.1 \pm 25.6$ \\
\hline TN801 & SWW & USSRWWN & Cardinal/FL302//AR Exp 494B-2-2/3/Fillmore/Cardinal//Jackson & $68.1 \pm 29.8$ & $78.7 \pm 17.0$ \\
\hline VA05W-258 & SWW & USSRWWN & VA98W-130//Coker9835/SS520 & $68.3 \pm 10.2$ & $50.7 \pm 20.3$ \\
\hline VA05W-414 & SWW & UESRWWN & Pio25W60//VA96W-606WS/Pio2691 & $70.3 \pm 18.4$ & $47.8 \pm 18.1$ \\
\hline MO040192 & SWW & UESRWWN & IL85-2872/MO10501 & $73.1 \pm 19.6$ & $68.2 \pm 21.7$ \\
\hline GA991209-6E33 & SWW & USSRWWN & GA901146/GA96004//AGS2000 & $74.6 \pm 31.6$ & $57.4 \pm 34.7$ \\
\hline LA99005UC-31-3-C & SWW & USSRWWN & Pio2548/Coker9835//AGS2000 & $76.4 \pm 32.5$ & $90.1 \pm 9.4$ \\
\hline LA02-923 & SWW & UESRWWN & PS8424//XY90-1B/TX851212 & $76.9 \pm 23.6$ & $82.4 \pm 10.2$ \\
\hline NYCalR-L & SWW & UESRWWN & reselection out of Caledonia & $80.2 \pm 12.1$ & $74.9 \pm 17.1$ \\
\hline VA05W-78 & SWW & USSRWWN & Tribute/AGS2000 & $81.1 \pm 17.2$ & $78.7 \pm 16.0$ \\
\hline NC03-6228 & SWW & USSRWWN & A92-4452//NC96BGTD1sib/NC96BGTA6sib & $81.1 \pm 14.0$ & $59.7 \pm 16.9$ \\
\hline W98008J1 & SWW & USSRWWN & IN82104B1-3-2/Williams & $81.1 \pm 25.7$ & $58.0 \pm 23.6$ \\
\hline OH03-41-45 & SWW & UESRWWN & IL91-14167/OH599 & $82.0 \pm 13.8$ & $87.1 \pm 4.3$ \\
\hline Arena exp. & SWW & UESRWWN & NASW84-345/Coker9835//OH419/OH389 & $82.9 \pm 20.8$ & $57.5 \pm 21.6$ \\
\hline ClarkFhb1NIL-98 & SWW & HWWGRU & Ning7840/Clark*7 & $85.0 \pm 7.8$ & $67.5 \pm 16.9$ \\
\hline VA03W-412 & SWW & UESRWWN & Roane/Pio2643//SS520 & $85.7 \pm 18.5$ & $77.7 \pm 11.6$ \\
\hline Coker 9553 & SWW & USSRWWN & 89M-4035A /Pio2580 & $86.7 \pm 14.6$ & $54.9 \pm 23.9$ \\
\hline D04-5012 & SWW & USSRWWN & NC96BGTD1/Mason & $88.4 \pm 14.9$ & $89.8 \pm 9.2$ \\
\hline GA991371-6E13 & SWW & USSRWWN & GA931521/2*AGS2000 & $89.1 \pm 14.9$ & $92.6 \pm 8.6$ \\
\hline GA991227-6A33 & SWW & USSRWWN & VA97W-24/AGS2000 & $93.1 \pm 8.5$ & $76.6 \pm 21.5$ \\
\hline LA01138D-52 & SWW & USSRWWN & LA841/LA422//AGS2000 & $94.4 \pm 9.7$ & $86.7 \pm 11.0$ \\
\hline AGS 2000 & SWW & USSRWWN & Pio.2555/PF84301//FL 302 & $94.5 \pm 12.2$ & $81.4 \pm 17.5$ \\
\hline LA98214D-14-1-2-B & SWW & USSRWWN & Shelby/LA87167D8-10-2 & $95.9 \pm 6.2$ & $95.8 \pm 6.3$ \\
\hline GA991336-6E9 & SWW & USSRWWN & GA92432//AGS2000/Pio26R61 & $97.5 \pm 5.5$ & $82.5 \pm 16.4$ \\
\hline
\end{tabular}

$1{ }^{\dagger} 35$ common cultivars with average PSS of set I and set II in greenhouse and field experiments.

$2 \quad{ }^{\ddagger} \mathrm{HWW}$, and SWW refer to hard red winter wheat, and soft winter wheat, respectively.

$3{ }^{\S}$ HWWGRU=USDA-ARS, Hard Winter Wheat Genetics Research Unit, Manhattan, KS; Tri-state FHB Nursery=2010Tri-state FHB Nursery; SRPN= Southern HWW Regional Performance Nursery; NRPN=

4 Northern HWW Regional Performance Nursery; RGON= HWW Regional Germplasm Observation Nursery; UESRWWN=Uniform Eastern Soft Red Winter Wheat Nurseries; USSRWWN=Uniform Southern 5 Soft Red Winter Wheat Nurseries.

6 "Mean of standard deviation 
1 Supplemental Table S2. Correlation coefficients of percentage of symptomatic spikelets (PSS) of FHB based on 35 common

2 accessions evaluated in 2009 fall (2009), 2010 fall (2010) and 2011 fall (2011I) field experiments with the first set, and 2011

3 (2011II) and 2012 (2012) field experiments with the second set.

\begin{tabular}{|c|c|c|c|c|}
\hline & 2009 & 2010 & $2011 \mathrm{I}$ & 2011II \\
\hline 2010 & $0.345^{*}$ & - & & \\
\hline $2011 \mathrm{I}$ & $0.499 * *$ & $0.665 * * *$ & - & \\
\hline 2011II & $0.415^{*}$ & $0.685^{* * *} *$ & $0.608^{* * *}$ & - \\
\hline 2012 & $0.401 *$ & $0.720 * * *$ & $0.681 * * *$ & $0.849 * * *$ \\
\hline
\end{tabular}

4

5

6 